\title{
Cannabinoid CB2 Agonist AM1710 Differentially Suppresses Distinct Pathological Pain States and Attenuates Morphine Tolerance and Withdrawal
}

\author{
Ai-Ling Li, Xiaoyan Lin, Amey S. Dhopeshwarkar, Ana Carla Thomaz, Lawrence M. Carey, \\ Yingpeng Liu, Spyros P. Nikas, Alexandros Makriyannis, Ken Mackie, \\ and Andrea G. Hohmann
}

Department of Psychological and Brain Sciences (A.-L.L., X.L., A.S.D., A.C.T., L.M.C., K.M., A.G.H.), Program in Neuroscience (A.C.T., L.M.C., K.M., A.G.H.), Genome, Cell and Developmental Biology Program (A.C.T., A.G.H.), and Gill Center for Biomolecular Science (K.M., A.G.H.), Indiana University, Bloomington, Indiana; and Center for Drug Discovery, Northeastern University, Boston, Massachusetts (Y.L., S.P.N., A.M.)

Received May 30, 2018; accepted November 26, 2018

\section{ABSTRACT}

AM1710 (3-(1,1-dimethyl-heptyl)-1-hydroxy-9-methoxy-benzo(c) chromen-6-one), a cannabilactone cannabinoid receptor 2 (CB2) agonist, suppresses chemotherapy-induced neuropathic pain in rodents without producing tolerance or unwanted side effects associated with CB1 receptors; however, the signaling profile of AM1710 remains incompletely characterized. It is not known whether AM1710 behaves as a broadspectrum analgesic and/or suppresses the development of opioid tolerance and physical dependence. In vitro, AM1710 inhibited forskolin-stimulated cAMP production and produced enduring activation of extracellular signal-regulated kinases $1 / 2$ phosphorylation in human embryonic kidney (HEK) cells stably expressing mCB2. Only modest species differences in the signaling profile of $\mathrm{AM} 1710$ were observed between HEK cells stably expressing $\mathrm{mCB} 2$ and hCB2. In vivo, AM1710 produced a sustained inhibition of paclitaxel-induced allodynia in mice. In paclitaxel-treated mice, a history of AM1710 treatment $(5 \mathrm{mg} / \mathrm{kg}$ per day $\times 12$ day, i.p.) delayed the development of antinociceptive tolerance to morphine and attenuated morphine-induced physical dependence. AM1710 $(10 \mathrm{mg} / \mathrm{kg}$, i.p.) did not precipitate CB1 receptor-mediated withdrawal in mice rendered tolerant to $\Delta^{9}$-tetrahydrocannabinol, suggesting that AM1710 is not a functional CB1 antagonist in vivo. Furthermore, $\operatorname{AM} 1710(1,3,10 \mathrm{mg} / \mathrm{kg}$, i.p.) did not suppress established mechanical allodynia induced by complete Freund's adjuvant (CFA) or by partial sciatic nerve ligation (PSNL). Similarly, prophylactic and chronic dosing with AM1710 (10 mg/kg, i.p.) did not produce antiallodynic efficacy in the CFA model. By contrast, gabapentin suppressed allodynia in both CFA and PSNL models. Our results indicate that AM1710 is not a broad-spectrum analgesic agent in mice and suggest the need to identify signaling pathways underlying CB2 therapeutic efficacy to identify appropriate indications for clinical translation.

\section{Introduction}

The opioid epidemic has intensified drug discovery efforts aimed at identifying efficacious alternatives to opioids that lack their undesirable properties. Opioids suppress diverse forms of pain, but chronic use results in tolerance and physical dependence (Yekkirala et al., 2017). Cannabinoids represent

The author(s) disclosed receipt of the following financial support for the research, authorship, and/or publication of this article: This work was supported by National Institute on Drug Abuse [Grant DA041229, DA045020, DA009158, DA021696] and National Cancer Institute [Grant CA200417]. L.M.C. is supported by National Institute on Drug Abuse [T32 Grant DA024628] and the Harlan Research Summer Scholars program.

https://doi.org/10.1124/mol.118.113233. an alternative to opioid analgesics (Pertwee, 2001). Two cannabinoid receptors have been well characterized: cannabinoid receptor 1 (CB1), which is abundantly expressed in the central nervous system (CNS) (Herkenham et al., 1991; Matsuda et al., 1993), and cannabinoid receptor 2 (CB2), which is predominantly expressed in immune cells and in the periphery (Galiègue et al., 1995). CB2 receptors may, nevertheless, be induced in the CNS under pathologic conditions (Zhang et al., 2003; Beltramo et al., 2006; Atwood and Mackie, 2010). CB2 receptor activation does not produce unwanted CNS-mediated side effects associated with CB1 (Malan et al., 2003; Guindon and Hohmann, 2008; Deng et al., 2015b). We recently reported that the $\mathrm{G}$ protein-biased $\mathrm{CB} 2$ agonist

ABBREVIATIONS: AM1710, 3-(1,1-dimethyl-heptyl)-1-hydroxy-9-methoxy-benzo(c) chromen-6-one; ANOVA, analysis of variance; BSA, bovine serum albumin; CB1, cannabinoid receptor 1; CB2, cannabinoid receptor 2; CFA, complete Freund's adjuvant; CNS, central nervous system; CP55940, (2)-cis-3-[2-hydroxy-4-(1,1-dimethylheptyl)-henyl]-trans-4-(3-hydroxypropyl)cyclohexanol; DMSO, dimethylsufoxide; ERK, extracellular signal-regulated kinases; hCB2, human cannabinoid receptor 1; HEK, human embryonic kidney; IP1, myo-inositol phosphate 1; KO, knockout; LY2828360, (8-(2-chlorophenyl)-2-methyl-6-(4-methylpiperazin-1-yl)- 9-(tetrahydro-2H-pyran-4-yl)-9H-purine); mCB2, mouse cannabinoid receptor 2; pERK 1/2, phosphorylated ERK1/2; PSNL, partial sciatic nerve ligation; PTX, pertussis toxin; TBS, Tris-buffered saline; $\Delta^{9}$-THC, $\Delta^{9}$-tetrahydrocannabinoil; WT, wild-type. 
LY2828360 (8-(2-chlorophenyl)-2-methyl-6-(4-methylpiperazin1-yl)- 9-(tetrahydro-2H-pyran-4-yl)-9H-purine) suppressed chemotherapy-induced neuropathic pain and attenuated development of morphine tolerance and physical dependence in neuropathic mice (Lin et al., 2017). Whether such effects are specific to LY2828360 or translate more broadly to other CB2 agonists with different signaling profiles remains unknown.

AM1710 (3-(1,1-dimethyl-heptyl)-1-hydroxy-9-methoxybenzo(c) chromen-6-one), a cannabilactone CB2 agonist, exhibits 54-fold selectivity for CB2 over CB1 (Khanolkar et al., 2007; Rahn et al., 2011) and lacks off-target activity at 63 sites evaluated (Rahn et al., 2011); however, AM1710 was recently found to be a low-potency CB1 inverse agonist in vitro (Dhopeshwarkar et al., 2017), but the in vivo functional impact of this property is unknown. We first characterized the signaling profile of AM1710 in vitro. Unlike CB1, which is largely conserved across diverse species, sequence heterogeneity in CB2 has been noted across species (Griffin et al., 2000; Brown et al., 2002; Bingham et al., 2007), which could lead to different pharmacologic responses to identical drugs (Mukherjee et al., 2004; Bingham et al., 2007). For example, $R, S$-AM1241 is an agonist at human CB2, but it is an inverse agonist at rat and mouse CB2 (Bingham et al., 2007). Consequently, caution must be taken when extrapolating effects observed in rodent models to humans. Therefore, in this study, we first characterized the in vitro signaling profile of AM1710 using both mouse and human CB2 receptors.

We validated antinociceptive efficacy of AM1710 and evaluated whether AM1710 could attenuate morphine tolerance and naloxone-precipitated opioid withdrawal in paclitaxeltreated mice as reported previously for LY2828360 (Lin et al., 2017). We also evaluated whether AM1710 acts as a functional CB1 antagonist in vivo by challenging mice treated chronically with $\Delta^{9}$-tetrahydrocannabinol $\left(\Delta^{9}\right.$-THC) with AM1710 or rimonabant to precipitate $\mathrm{CB} 1$-dependent cannabinoid withdrawal.

Finally, we evaluated whether AM1710 is a broad-spectrum analgesic, efficacious across mechanistically distinct inflammatory and neuropathic pain states. AM1710 exhibits antinociceptive efficacy in multiple preclinical models of neuropathic pain (Deng et al., 2012; Wilkerson et al., 2012; Rahn et al., 2014; Deng et al., 2015b). Despite the promising preclinical therapeutic potential of AM1710, whether AM1710 suppresses allodynia in mechanistically distinct inflammatory and neuropathic pain models remains poorly understood. This evaluation is crucial because our recent studies suggest that the antiallodynic efficacy of the CB2preferring agonist GW405833 is CB1-mediated and not CB2-mediated (Li et al., 2017). Therefore, a secondary goal of this study was to characterize possible antihyperalgesic effects of AM1710 in a model of inflammatory pain induced by intraplantar injection of complete Freund's adjuvant (CFA) and a model of neuropathic pain induced by partial sciatic nerve ligation (PSNL) in mice. We compared the antinociceptive efficacy of AM1710 to gabapentin, which shows efficacy in both models (Patel et al., 2001). To verify whether engagement of CB2 by a structurally distinct cannabinoid with a different in vitro signaling profile was antiallodynic in these two pain models, we administered the mixed CB1/CB2 agonist CP55940 to CB1 knockout (KO) mice. CP55940 binds to CB1 and CB2 with similar affinities in vitro (Felder et al., 1995) and does not exhibit functionally biased signaling at CB2 (Atwood et al., 2012). We previously showed that high doses of CP55940 (10 mg/kg, i.p.) produced CB2-mediated antiallodynia in paclitaxel-treated CB1 KO mice (Deng et al., 2015a). Thus, CB1 KO mice were used in these latter studies to eliminate possible confounding effects of CP55940 (i.e., in producing CB1-mediated motor impairment) from assessments of antinociceptive efficacy.

\section{Materials and Methods}

\section{Animals}

Adult mice (25-35 g) were used in this study. Number, strain and sex of animals are indicated for each group in the figure legends. CB2 KO mice (bred at Indiana University) and wild-type (WT) on a C57BL/6J background (bred at Indiana University or purchased from The Jackson Laboratory, Bar Harbor, ME), and CB1 KO mice (bred at Indiana University) on a CD1 background and CD1 WT controls ((bred at Indiana University or purchased from Charles River Laboratories, Wilmington, MA) were included. Animals were single-housed at relatively constant temperature $\left(73 \pm 2^{\circ} \mathrm{F}\right)$ and humidity $(45 \%)$ under 12-hour light/dark cycles. All the experimental procedures were approved by Bloomington Institutional Animal Care and Use Committee of Indiana University and followed the guidelines for the treatment of animals of the International Association for the Study of Pain (Zimmermann, 1983).

\section{Chemicals}

AM1710 (Khanolkar et al., 2007) was synthesized in the Makriyannis Laboratory by S.P.N, and Y.L. (Boston, MA); CP55940 was purchased from Cayman Chemical Company (Ann Arbor, MI) or was obtained from the National Institute of Drug Abuse Drug Supply Service (Bethesda, MD). AM1710, morphine (Sigma-Aldrich, St. Louis, MO), and CP55940 were dissolved in a vehicle containing dimethylsulfoxide (Sigma-Aldrich), emulphor (Alkamuls EL 620L; Solvay, Princetone, NJ), ethanol (Sigma-Aldrich), and 0.9\% saline (Aquilite System, Hospira Inc, Lake Forest, IL) at a ratio of 5:2:2:16. Gabapentin (Spectrum Chemical, New Brunswick, NJ) or naloxone (Sigma-Aldrich) was dissolved in $0.9 \%$ saline. Paclitaxel (Tecoland Corporation, Irvine, CA) was dissolved in a cremophor-based vehicle made of Cremophor EL (Sigma-Aldrich), ethanol, 0.9\% saline at ratio of $1: 1: 18$ as described previously (Deng, et al., 2015b). $\Delta^{9}$-THC (National Institute on Drug Abuse) was dissolved in a vehicle of 95\% ethanol, cremophor, and sterile saline in a ratio of 1:1:18 respectively. Drugs were delivered via intraperitoneal injection to mice in a volume of 5 or $10 \mathrm{ml} / \mathrm{kg}$.

\section{Cell Culture}

HEK293 cells stably expressing mouse CB2 (HEK mCB2) or human CB2 (HEK hCB2) receptors were generated, expanded, and maintained in Dulbecco's modified Eagle's medium with $10 \%$ fetal bovine serum and penicillin/streptomycin (GIBCO, Carlsbad, CA) at $37^{\circ} \mathrm{C}$ in $5 \% \mathrm{CO}_{2}$ (Atwood et al., 2012). Selection antibiotic/reagent was G418 at a concentration of $400 \mathrm{mg} / \mathrm{ml}$. For ease of immunostaining, an aminoterminal hemagglutinin epitope tag was introduced into the CB2 receptor (Atwood et al., 2012).

\section{Forskolin-Stimulated cAMP Accumulation Assay}

Forskolin-stimulated cAMP accumulation assays were optimized using PerkinElmer's LANCE ultra cAMP kit (cat. no. TRF0262; PerkinElmer, Boston, MA) as per the manufacturer's instructions. All assays were performed at room temperature using 384-optiplates (cat. no. 6007299; PerkinElmer). Briefly, cells were resuspended in $1 \times$ stimulation buffer $(1 \times$ Hank's balanced salt solution, $5 \mathrm{mM}$ HEPES, $0.5 \mathrm{mM}$ IBMX, $0.1 \%$ bovine serum albumin, $\mathrm{pH} 7.4$, made 
fresh on the day of experiment). Cells (HEK transfected with mouse and human CB2) were incubated for 1 hour at $37^{\circ} \mathrm{C}, 5 \% \mathrm{CO}_{2}$, and humidified air and then transferred to a 384-optiplate (500 cells $/ \mu \mathrm{l}$, $10 \mu \mathrm{l}$ ), followed by stimulation with drugs/compounds and forskolin ( $1 \mu \mathrm{M}$ final concentration) (as indicated) prepared in $1 \times$ stimulation buffer for defined time points. Cells-only wells were treated as basal. No forskolin, no drug, and drug-only (no forskolin) controls for every defined time point were also included. For experiments involving pertussis toxin (PTX), cells were incubated overnight with $100 \mathrm{ng} / \mathrm{ml}$ PTX at $37^{\circ} \mathrm{C}, 5 \% \mathrm{CO}_{2}$, and humidified air. After stimulation for the appropriate time, cells were lysed by the addition of $10 \mu \mathrm{l} \mathrm{Eu-cAMP}$ tracer working solution $(4 \times$, made fresh in $1 \times$ lysis buffer supplied with the kit, under subdued light conditions) and $10 \mu \mathrm{l}$ of Ulight anticAMP working solution $(4 \times$, made fresh in $1 \times$ lysis buffer $)$ and further incubated for 1 hour at room temperature. Plates were then read in the TR FRET mode on an Enspire plate reader (PerkinElmer). Assays were performed in triplicate unless otherwise mentioned.

\section{Detection of Phosphorylated Extracellular Signal-Regulated Kinases 1/2 and JNK}

HEK mouse and human CB2 cells were seeded on poly-D-lysinecoated 96 -well plates $\left(75,000\right.$ cells/well) and grown overnight at $37^{\circ} \mathrm{C}$, $5 \% \mathrm{CO}_{2}$, humidified air. For pertussis toxin (PTX)-treated experiments, cells were treated overnight with $100 \mathrm{ng} / \mathrm{ml}$ PTX at $37^{\circ} \mathrm{C}$, $5 \% \mathrm{CO}_{2}$, humidified air. The following day, cells were serum-starved for 5 hours at $37^{\circ} \mathrm{C}$ in $5 \% \mathrm{CO}_{2}$, humidified air. The medium was then replaced by Hanks' buffered saline/bovine serum albumin $(0.2 \mathrm{mg} / \mathrm{ml})$, and cells were challenged with drugs/compounds for the indicated times. Wells containing cells only were treated as basal (control) condition. After drug incubation, plates were emptied and quickly fixed with ice-cold $4 \%$ paraformaldehyde for 20 minutes, followed by ice-cold methanol with the plate maintained at $-20^{\circ} \mathrm{C}$ for 15 minutes. Plates were then washed with TBS/0.1\% Triton X-100 for 25 minutes $(5 \times 5$-minute washes). The wash solution was then replaced by Odyssey blocking buffer (LI-COR Biotechnology, Lincoln, NE) and incubated further for 90 minutes with gentle shaking at room temperature. Blocking solution was then removed and replaced with blocking solution containing anti-phospho- extracellular signalregulated kinases (ERK)1/2 (p44/42) antibody or total ERK1/2 (1: 150; antibody no. 9101 or 9102 respectively; Cell Signaling Technology, Danvers, MA) and was shaken overnight at $4^{\circ} \mathrm{C}$. For the JNK assay, blocking solution was replaced with blocking solution containing anti-phospho JNK (P46/54) antibody (1:100; antibody no. 9251; Cell Signaling Technology). The next day, plates were washed with TBS containing $0.05 \%$ Tween-20 for 25 minutes $(5 \times 5$-minute washes). Secondary antibody, donkey anti-rabbit conjugated with IR800 dye (Rockland, Limerick, PA), prepared in blocking solution, was added and gently shaken for 1 hour at room temperature. The plates were then again washed five times with TBS/0.05\% Tween-20 solution. The plates were patted dry and scanned using LI-COR Odyssey scanner. pERK1/2 activation (expressed in \%) were calculated by dividing average integrated intensities of the drug treated wells by average integrated intensities of vehicle-treated wells. All assays were performed in triplicate, unless otherwise mentioned. Normalization of background fluorescence was achieved by subtracting relative fluorescence units (RFU) obtained from wells treated with only secondary antibody (no primary antibody) from wells with total RFU (wells treated with both primary and secondary antibody).

\section{Partial Sciatic Nerve Ligation-Induced Neuropathic Pain}

PSNL was performed as described in our previously published work ( $\mathrm{Li}$ et al., 2017). Briefly, under isoflurane anesthesia, a longitudinal incision $(1.0-1.5 \mathrm{~cm})$ was made in the proximal right thigh to expose the sciatic nerve. One-third to one-half of the sciatic nerve was ligated just above its trifurcation using 8-0 silk suture (DA-2526N; Sharpoint, Reading, PA). The incision was then closed in layers. Animals were allowed at least 2 weeks to recover and fully develop neuropathic pain.

\section{CFA-Induced Inflammatory Pain}

CFA was diluted with an equal volume of sterile saline, and $20 \mu \mathrm{l}$ of this mixture was injected subcutaneously into the plantar surface of the right hind paw.

\section{Paclitaxel-Induced Peripheral Neuropathic Pain}

Paclitaxel (4 mg/kg, i.p.) was administered to animals four times on alternate days (cumulative dose, $16 \mathrm{mg} / \mathrm{kg}$, i.p.) to induce painful peripheral neuropathy, as previously described by our group (Deng et al., 2015b).

\section{Assessment of Mechanical Allodynia}

As previously described ( $\mathrm{Li}$ et al., 2017), mice were placed in individual transparent Plexiglass chambers on an elevated mesh platform and allowed to habituate for minimum of 30 minutes before testing. A semiflexible tip connected to an electronic von Frey anesthesiometer (IIITC Life Science Inc., Woodland Hills, CA) was applied vertically to the midplantar region of the hindpaw with gradually increased force. The force in grams when the animal withdrew the paw was recorded. Each paw was tested twice with an interval of several minutes between stimulations to avoid sensitization. Mechanical paw withdrawal thresholds in grams (g) were averaged, respectively, for each paw for mice subjected to a unilateral PSNL or CFA injection. In paclitaxel-treated mice where allodynia is observed bilaterally in each paw, paw withdrawal thresholds were calculated for each paw as described already and subsequently averaged across paws to obtain a single dependent measure per animal for each stimulus modality at a given time point.

\section{Assessment of Cold Allodynia}

The duration of responding to cold (seconds) was evaluated after the assessment of responsiveness to mechanical stimulation for pain models in which cold allodynia is prominent, as we have previously published (Lin et al., 2017). A 1-ml syringe with the needle removed was filled with acetone (Sigma-Aldrich). An acetone bubble (5 to $6 \mu \mathrm{l}$ ) was formed at the tip of the syringe by applying slight pressure to the plunger. The acetone bubble was then gently applied to the plantar surface of the hindpaw with care taken to avoid contacting the paw with the syringe tip and applying mechanical pressure. The time in seconds spent attending to (i.e., elevating, biting, licking, shaking, or flinching) the paw stimulated with acetone was measured in triplicate for each paw.

\section{Evaluation of Opioid or CB1 Receptor-Mediated Withdrawal Symptoms}

Naloxone-Precipitated Opioid Withdrawal. C57BL/6J mice receiving prior chronic treatments with vehicle, morphine alone (10 mg/kg per day, i.p.) or a combination of morphine with AM1710 was first challenged with saline vehicle $(0.9 \%$ saline, i.p.) 30 minutes after the last treatment. Thirty minutes after the saline vehicle challenge, animals were then challenged with naloxone $(5 \mathrm{mg} / \mathrm{kg}$, i.p.) to induce opioid withdrawal. Mice were videotaped, and the number of jumps was scored in 5-minute intervals for a total observation period of 30 minutes after challenge with either vehicle or naloxone.

Rimonabant-Precipitated Cannabinoid CB1 ReceptorDependent Withdrawal. Naïve C57BL/6J mice received oncedaily injections of $\Delta^{9}$-THC ( $50 \mathrm{mg} / \mathrm{kg}$, i.p.) for 9 days. Thirty minutes after the last injection of $\Delta^{9}$-THC on day 9 , all animals were first challenged with vehicle. Then, 30 minutes after vehicle challenge, half of the animals received a second challenge with AM1710 (10 $\mathrm{mg} / \mathrm{kg}$, i.p.), and the other half of the animals received a second 
challenge with the $\mathrm{CB} 1$ antagonist rimonabant $(10 \mathrm{mg} / \mathrm{kg}$, i.p.). Behavior was videotaped for 30 minutes immediately after vehicle, rimonabant, or AM1710 challenge. The numbers of front paw tremors, headshakes, grooming, and rearing behaviors were counted by an investigator blinded to treatment conditions according to methods described in our previously published work (Li et al., 2017).

\section{General In Vivo Experimental Protocol}

Mechanical and cold responsiveness was assessed 30 minutes after pharmacologic manipulations.

Experiment 1. We investigated whether chronic pretreatment with AM1710 in phase I can block the development of tolerance to morphine in phase II in paclitaxel-treated mice. Male C57BL/J6 mice were injected with paclitaxel ( $4 \mathrm{mg} / \mathrm{kg}$, i.p.) on alternate days on four occasions as described already herein to induce a painful peripheral neuropathy. After paclitaxel-induced neuropathic pain was fully established, mice were randomly assigned to one of three groups. The treatment period was composed of two phases, phase I and phase II, with 4 days separating the two phases. The protocol used here was identical to that used in our previously published work to show that the G protein-based CB2 agonist LY2828360 suppressed paclitaxelinduced neuropathic pain and blocked development of tolerance to morphine in paclitaxel-treated mice (Lin et al., 2017). One group of mice received daily intraperitoneal injections of AM1710 for 12 consecutive days ( $5 \mathrm{mg} / \mathrm{kg}$ per day, i.p.) during phase I, followed by daily intraperitoneal injections of morphine $(10 \mathrm{mg} / \mathrm{kg}$ per day, i.p.) for 12 days during phase II [i.e., AM1710 (I)-morphine (II)]. A second group of mice received parallel daily injections of vehicle for 12 days during phase I, followed by daily injections of morphine in phase II [i.e., vehicle (I)-morphine (II)]. A third group of mice received parallel daily vehicle administration in both phase I and II [vehicle (I)vehicle (II)]. Mechanical and cold sensitivity levels were assessed on days $1,4,8$, and 12 in phase I and day $16,19,23,27$ in phase II.

At the end of all treatments, all mice were challenged (intraperitoneally) with vehicle, followed by naloxone (intraperitoneally), as described already herein, and withdrawal behaviors were recorded for 30 minutes after each challenge. Changes in body temperature $\left({ }^{\circ} \mathrm{C}\right)$ and body weight (grams) induced by challenge with vehicle and naloxone, respectively, were also recorded at 30 minutes and 2 hours postinjection.

Experiment 2. We investigated whether AM1710 can precipitate CB1 receptor-mediated withdrawal in mice chronically treated with $\Delta^{9}$-THC, consistent with our recent report that AM1710 may behave as CB1 antagonist in vitro (Dhopeshwarkar et al., 2017). Naïve C57BL/6J mice received once-daily dosing with $\Delta^{9}$-THC $(50 \mathrm{mg} / \mathrm{kg}$ per day, i.p.) for 9 days and were then challenged with vehicle, rimonabant, or AM1710 as described herein. The withdrawal behaviors were recorded for 30 minutes after each challenge as described in our previously published work ( $\mathrm{Li}$ et al., 2017).

Experiment 3. We assessed the dose response of $\operatorname{AM} 1710$ (1, 3, $10 \mathrm{mg} / \mathrm{kg}$, i.p.) in suppressing established inflammatory pain induced by CFA using both WT and CB2 KO mice. The dose response of gabapentin in suppressing inflammatory nociception in the same pain model was assessed in WT mice, in parallel, as a positive control.

We further evaluated the antiallodynic effect of prophylactic chronic treatment with AM1710 (10 mg/kg, i.p.) in mice receiving a unilateral intraplantar injection of CFA. Comparisons were made with gabapentin (50 mg/kg, i.p.) in C57BL/J6 mice. AM1710 $(10 \mathrm{mg} / \mathrm{kg}$, i.p.) or gabapentin $(50 \mathrm{mg} / \mathrm{kg}$, i.p.) was injected 30 minutes before CFA injection on day 1 and continued once daily for 12 consecutive days for AM1710 and for 8 consecutive days for gabapentin.

Experiment 4. We assessed the dose response of AM1710 (1, 3, $10 \mathrm{mg} / \mathrm{kg}$, i.p.) in suppressing established neuropathic pain induced by PSNL using both WT and CB2 KO mice. The dose response of gabapentin in suppressing PSNL-induced neuropathic nociception was assessed in WT mice, in parallel, as a positive control.
Experiment 5. We evaluated whether CP55940 (3 and $10 \mathrm{mg} / \mathrm{kg}$, i.p.) produced antiallodynic effects through activation of CB2 receptors in CB1 KO mice subjected to PSNL-induced neuropathic pain and CFA-induced inflammatory pain.

\section{Statistical Analysis}

Two-way mixed analysis of variance (ANOVA) was used to analyze the main effect of time and of groups, as well as interaction between time and groups. Two-way repeated measures ANOVA was used for the analyses of the main effect of time, the main effect of paws, and the interactions between time and paws. One-way ANOVA was used to detect the group differences where no time course was involved (e.g., group differences in jumping behavior after naloxone challenge). Bonferroni post hoc (for all comparisons) and Bonferroni multiple comparison tests (for making a restricted set of comparisons) were performed for all pairwise comparisons. Planned comparison $t$ tests (paired or unpaired, as appropriate) were used for specific comparisons of interest as indicated. SPSS 24 (IBM Corporation, Armonk, NY) was used to analyze in vivo data; GraphPad Prism version 5.02 (GraphPad Software, San Diego, CA) was used to analyze in vitro data. $P<0.05$ was considered statistically significant. Figures were generated using GraphPad Prism version 5.02 (GraphPad Software). Data are expressed as mean \pm S.E.M.

\section{Results}

AM1710 Inhibited Forskolin-Stimulated cAMP Accumulation in HEK Cells Expressing mCB2 or hCB2, but the Kinetics of Inhibition Differed between mCB2 and hCB2. In HEK cells stably expressing mCB2, cAMP levels differed between treatments $\left(F_{5,12}=609, P<0.001\right)$ and varied over time $\left(F_{4,48}=108.2, P<0.001\right)$ (Fig. $\left.1 \mathrm{~A}\right)$. The interaction between treatment and time was significant $\left(F_{20,48}=44.58\right.$, $P<0.001$ ) (Fig. 1A). Forskolin persistently increased cAMP levels in cells incubated with vehicle, starting at 5 minutes $(P<0.001)$. The presence of CP55940 $(1 \mu \mathrm{M}$ final concentration) $(P<0.001)$ or AM1710 $(1 \mu \mathrm{M}$ final concentration $)(P<$ 0.001 ) attenuated forskolin-induced cAMP levels at 5 minutes. Although CP55940 exhibited a stronger inhibitory effect than AM1710 at 5 minutes $(P<0.001)$, the inhibitory effect of AM1710 outlasted that of CP55940, and the inhibition induced by AM1710 dissipated by 15 minutes. Aftere the brief inhibition of cAMP levels by CP55940 or AM1710, cAMP levels exceeded those in cells treated with forskolin alone $(P<0.001)$ (Fig. 1A). In the absence of forskolin, CP55940 or AM1710 alone did not change cAMP levels, as no differences were observed between these conditions and the basal/no forskolin condition with one exception; AM1710 treatment alone decreased cAMP levels below the basal/no forskolin level at 10 minutes $(P=0.012)$. Pertussis toxin (PTX) pretreatment abolished the decrease in forskolin-stimulated cAMP induced by either CP55940 ( $1 \mu \mathrm{M}$ final concentration) or AM1710 (1 $\mu \mathrm{M}$ final concentration) in HEK cells stably expressing mCB2 (Fig. 1B). Despite the significant changes in cAMP over time $\left(F_{3,24}=29.51, P<0.001\right)$ and significant effects of both treatment $\left(F_{3,8}=1443, P<0.001\right)$ and interaction $\left(F_{9,24}=2.795, P=0.021\right)$, no differences were detected between treatments with forskolin stimulation at any time point in the PTX-treated cells $(P>0.235)$ (Fig. 1B).

In HEK cells stably expressing hCB2, cAMP levels differed between treatments $\left(F_{5,12}=412.6, P<0.001\right)$ and varied over time $\left(F_{4,48}=123.9, P<0.001\right)$ (Fig. $\left.1 C\right)$. The interaction between treatment and time was significant $\left(F_{20,48}=47.54\right.$, 
mCB2

A
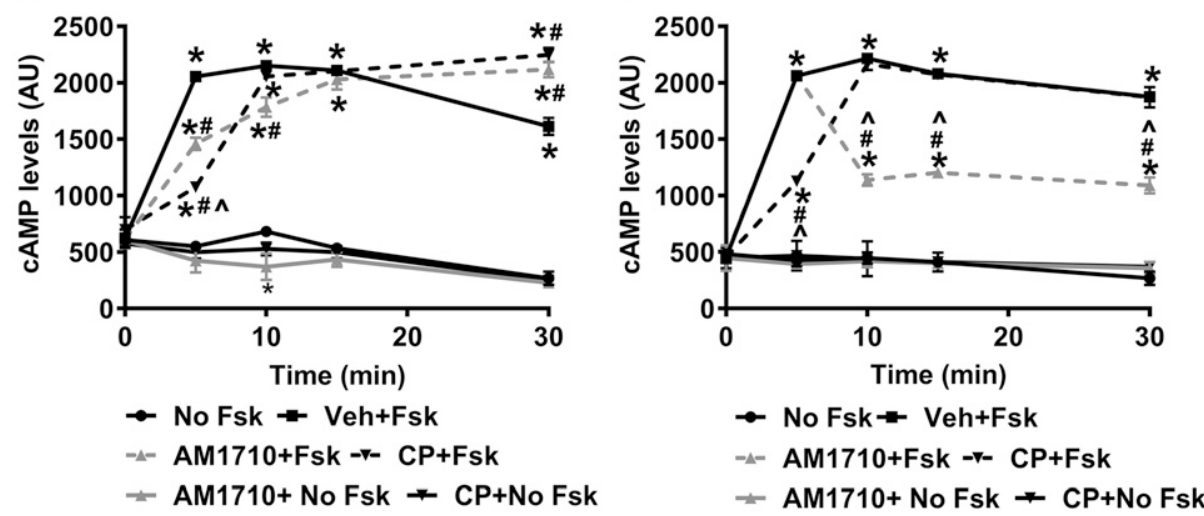

B

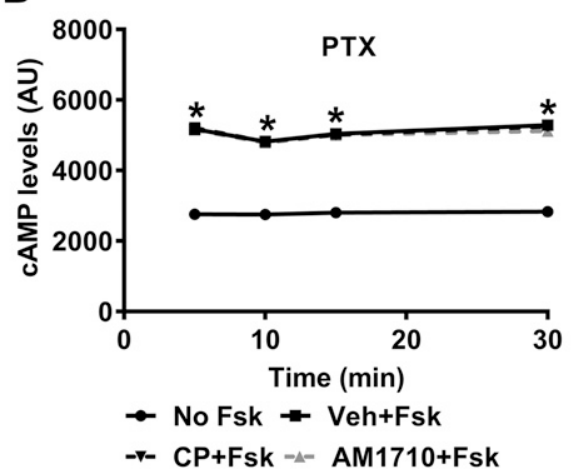

C

hCB2

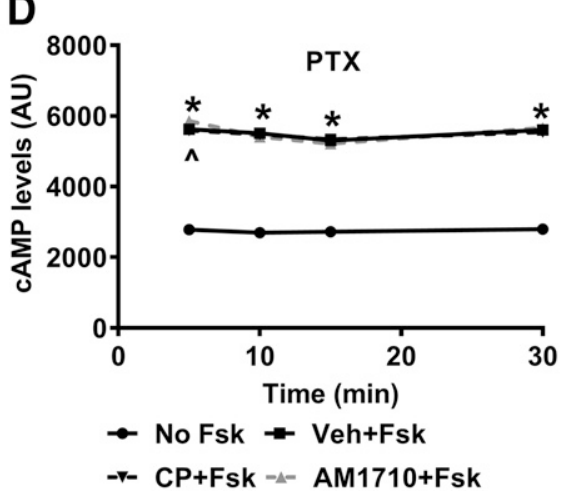

Fig. 1. AM1710 inhibited forskolin-stimulated cAMP in HEK cells expressing mCB2 and hCB2, but the kinetics of inhibition differed between mCB2 and hCB2. (A) In HEK cells expressing mCB2, both CP55940 and AM1710 reduced cAMP levels at 5 minutes. The inhibitory effect of AM1710 lasted longer than CP55940 and dissipated by 15 minutes. (B) After treating HEK cells expressing mCB2 with PTX, both CP55940 and AM1710 failed to reduce cAMP levels at all time points examined. (C) In HEK cells expressing hCB2, CP55940 induced early reduction of cAMP at 5 minutes, which lasted up to 10 minutes, whereas AM1710 induced a delayed (at 10 minutes) but longlasting (up to 30 minutes) decrease in cAMP. (D) After treating HEK cells expressing hCB2 with PTX, both CP55940 and AM1710 failed to reduce cyclase levels at all time points examined. $* P<0.05$ vs. No Fsk; ${ }^{\#} P<0.05$ vs. Veh + Fsk, ${ }^{\wedge} P<0.05$ significant difference between CP + Fsk and AM1710 + Fsk (two-way mixed ANOVA, followed by Bonferroni' post hoc test). AU, arbitrary unit; CP, CP55940; Fsk, forskolin; hCB2, human CB2 receptors; $\mathrm{mCB} 2$, mouse CB2 receptors; Veh, vehicle. $n=3$ for each group.
$P<0.001$ ) (Fig. 1C). Similarly, forskolin persistently increased cAMP levels in cells incubated with vehicle starting at 5 minutes $(P<0.001)$; however, only CP55940 produced early inhibition of forskolin-induced cAMP levels at 5 minutes $(P<0.001)$ (Fig. 1C). By contrast, AM1710 induced a delayed and persistent inhibition of forskolin-stimulated cAMP levels, starting at 10 minutes $(P<0.001)$ (Fig. $1 \mathrm{C})$. Like the HEK cells stably expressing mCB2, CP55940 and AM1710 alone did not change the cAMP levels in cells stably expressing hCB2 $(P=1)$. PTX pretreatment blocked the inhibition of forskolinstimulated cAMP produced by either CP55940 $(1 \mu \mathrm{M}$ final concentration) or AM1710 (1 $\mu \mathrm{M}$ final concentration) in HEK cells stably expressing hCB2 (Fig. 1D). Despite the significant changes over time $\left(F_{3,24}=22.95, P<0.001\right)$ and significant effects of both treatment $\left(F_{3,8}=2472, P<0.001\right)$ and interaction $\left(F_{9,24}=3.391, P=0.008\right)$, no differences were detected between treatments with forskolin stimulation at any time point $(P>0.831)$, with one exception: in the presence of forskolin, AM1710 increased cAMP levels compared with forskolin alone at 5 minutes in PTX-treated cells $(P=0.048)$ (Fig. 1D).

AM1710 Activated ERK1/2 Phosphorylation in HEK Cells Expressing mCB2 or hCB2, but the Kinetics of Inhibition Differed between mCB2 and hCB2. In HEK cells stably expressing mCB2, phosphorylated ERK1/2 levels changed over time across the treatments $\left(F_{4,32}=157.7, P<\right.$ 0.001) (Fig. 2A). Both CP55940 (1 $\mu \mathrm{M}$ final concentration) and AM1710 (1 $\mu \mathrm{M}$ final concentration) increased phosphorylated ERK1/2 levels $\left(F_{3,8}=969.4, P<0.001\right)$. This increase was time-dependent $\left(F_{12,32}=50.43, P<0.001\right)$. Both AM1710 and CP55940 induced a rapid (starting at 5 minutes, $P<0.001$ ) and long-lasting increase in ERK1/2 phosphorylation (up to 30 minutes, $P<0.001$ ). The ERK1/2 phosphorylation induced by AM1710 was consistent throughout the observation interval, whereas CP55940-induced ERK1/2 phosphorylation was more variable and biphasic (Fig. 2A). The vehicle slightly increased ERK1/2 phosphorylation compared with the basal condition at $0(P=0.01)$ and 5 minutes $(P=0.006)$ but did not differ from basal levels at any of the remaining time points $(P>0.764)$. PTX pretreatment differentially affected ERK1/2 phosphorylation levels between treatments $\left(F_{3,8}=35.64, P<\right.$ $0.001)$ and over time $\left(F_{3,24}=167.8, P<0.001\right)$ (Fig. $2 B$ ). Significant interaction between treatment and time was observed $\left(F_{9,24}=57.28, P<0.001\right)$, and PTX pretreatment abolished the rapid activation of ERK1/2 induced by AM1710 (1 $\mu \mathrm{M}$ final concentration) at 5 minutes (Fig. 2B). Interestingly, after PTX pretreatment, ERK1/2 was dephosphorylated by 5 minutes of CP55940 treatment relative to the vehicle group $(P<0.001)$ (Fig. 2B). In PTX-treated cells, phosphorylation levels of ERK1/2 were increased after 30-minute treatment with either AM1710 or CP55940 ( $P<0.001)$ (Fig. 2B).

Similarly, CP55940 (1 $\mu \mathrm{M}$ final concentration) and AM1710 ( $1 \mu \mathrm{M}$ final concentration) both induced ERK1/2 phosphorylation in HEK cells stably expressing hCB2 $\left(F_{3,8}\right.$ $=109.2, P<0.001$ ), and the level of phosphorylated ERK1/2 changed over time $\left(F_{4,32}=286.8, P<0.001\right)($ Fig. $2 \mathrm{C})$. The significant interaction between treatment and time $\left(F_{12,32}=\right.$ 107.6, $P<0.001$ ) indicates that the ERK1/2 phosphorylation 


\section{mCB2}

A

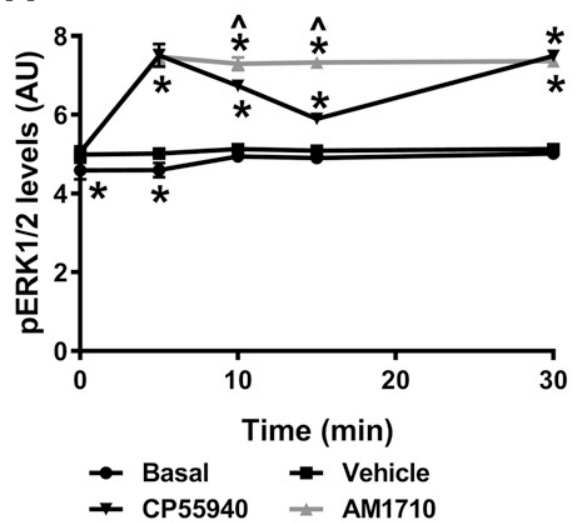

B

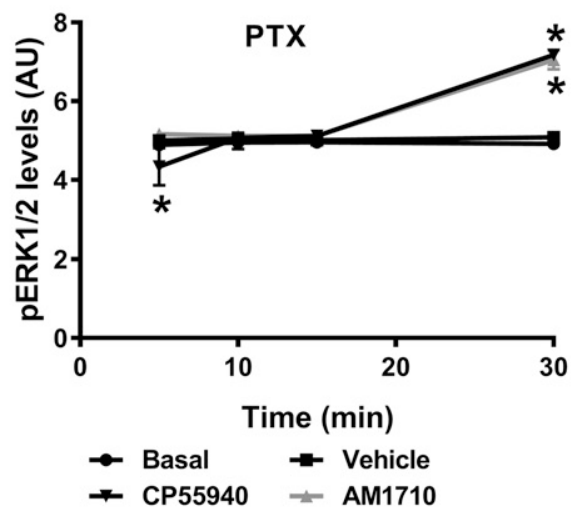

E

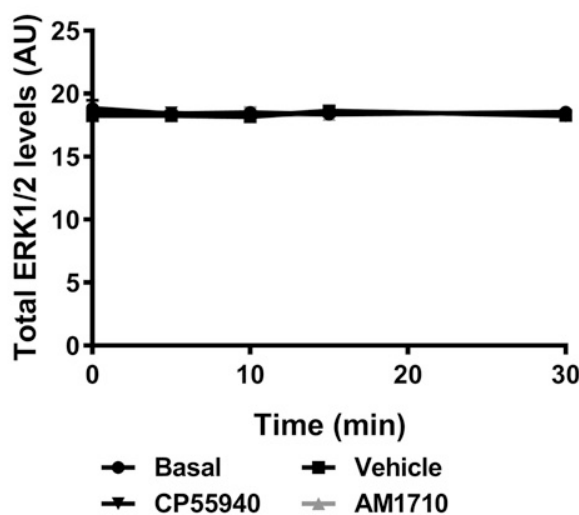

hCB2

C

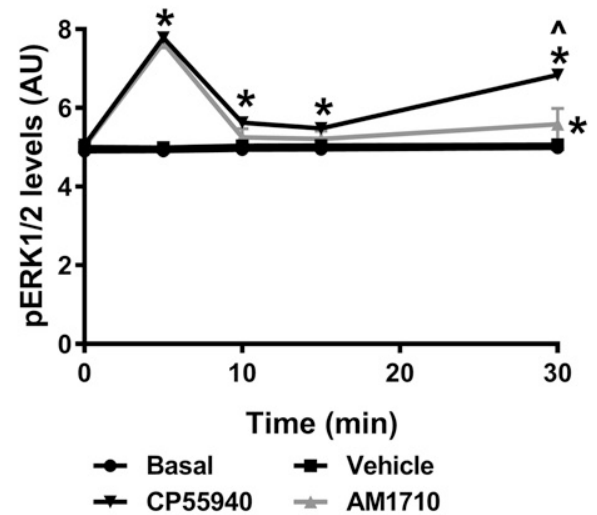

D

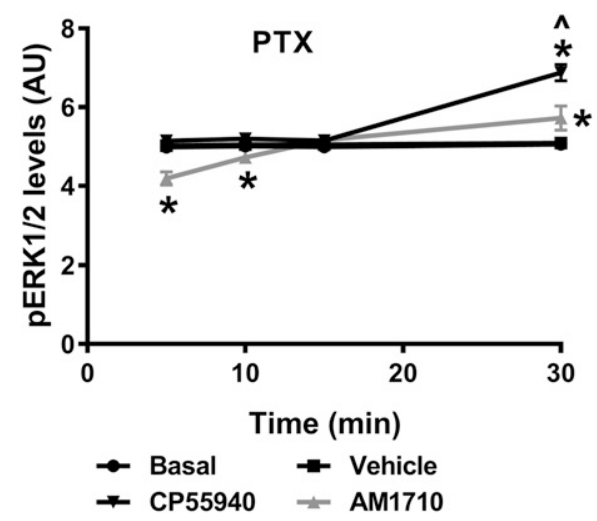

$\mathbf{F}$

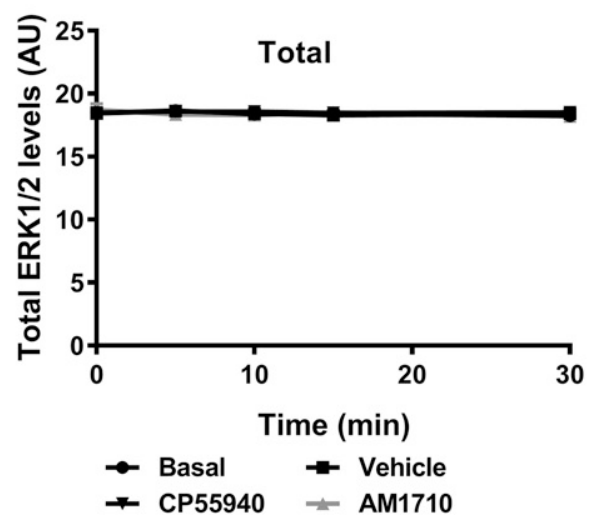

Fig. 2. AM1710 activated CB2 receptorand $\mathrm{G}$ protein-dependent ERK1/2 phosphorylation in HEK cells expressing $\mathrm{mCB} 2$ and hCB2, but the kinetics of inhibition differed between $\mathrm{mCB} 2$ and hCB2. (A) In HEK cells expressing mCB2, AM1710 consistently induced ERK1/2 phosphorylation at all time points examined, whereas CP55940 biphasically increased ERK1/2 phosphorylation. (B) After treating HEK cells expressing mCB2 with PTX, both CP55940 and AM1710 failed to induce ERK1/2 phosphorylation except at 30 minutes. By contrast, CP55940 reduced ERK1/2 phosphorylation at 5 minutes after PTX treatment. (C) In HEK cells expressing hCB2, both CP55940 and AM1710 induced rapid phosphorylation of ERK1/2 at 5 minutes, followed by a reduction in ERK1/2 phosphorylation and an increase in phosphorylation at 30 minutes. (D) After treating HEK cells expressing hCB2 with PTX, AM1710 reduced ERK1/2 phosphorylation at the 5-and 10- minute time points but slightly increased ERK1/2 phosphorylation at 30 minutes. CP55940 showed only activation of ERK1/2 phosphorylation at 30 minutes. Total ERK1/2 levels did not differ between conditions in HEK cells expressing mCB2 (E) or hCB2 (F). $* P<0.05$ vs. vehicle; ${ }^{\wedge} P<0.05$ significant difference between CP55940 and AM1710 (two-way mixed ANOVA, followed by Bonferroni's post hoc test). AU, arbitrary unit; hCB2, human $\mathrm{CB} 2$ receptors; mCB2, mouse CB2 receptors. $n=3$ for each group. induced by CP55940 and AM1710 was also time-dependent. Specifically, both CP55940 and AM1710 induced rapid ERK1/2 phosphorylation at 5 minutes $(P<0.001)$, followed by a reduction in phosphorylation and then an increase at 30 minutes, which was greater for CP55940 $(P<0.001)$ (Fig. 2C). No difference in ERK1/2 phosphorylation was observed between basal and vehicle conditions $(P=1)$ (Fig. 2C). After PTX pretreatment, CP55940 and AM1710 affected ERK1/2 phosphorylation levels in very distinct ways $\left[F_{3,8}=50.01, P<0.001\right.$ (treatment) $F_{3,24}=160.3, P<0.001$ (time); $F_{9,24}=58.5, P<0.001$ (interaction)] (Fig. 2D). AM1710 induced rapid dephosphorylation of ERK1/2 relative to the vehicle group at $5(P<0.001)$ and $10(P=0.007)$ minutes and then slightly increased phosphorylation of ERK1/2 at 30 minutes $(P<0.001)$. By contrast, CP55940 induced delayed ERK1/2 phosphorylation at 30 minutes only $(P<0.001)$ (Fig. 2D). The total ERK1/2 levels did not differ among treatments over time in cells stably expressed mCB2 $\left[F_{3,8}=09.267, P=0.848\right.$ (treatment); $F_{4,32}=0.965, P=0.440$ (time) $F_{12,32}=0.546, P=0.868$ (interaction)] (Fig. 2E) or hCB2 $\left[F_{3,8}=0.481, P=0.704\right.$ (treatment); $F_{4,32}=1.114, P=0.367$ (time); $F_{12,32}=1.034, P=$ 0.443 (interaction)] (Fig. 2F).

AM1710 Phosphorylated JNK 46/54 Similarly in HEK Cells Expressing mCB2 or hCB2. In HEK cells stably expressing mCB2, overall, the phosphorylation of JNK 46/54 

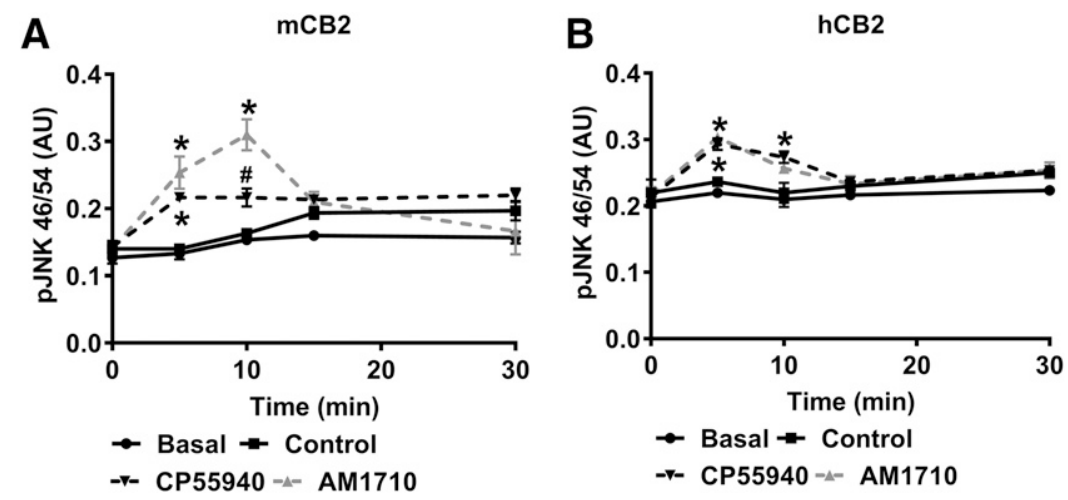

Fig. 3. AM1710 increased phosphorylation of JNK 46/54 similarly in HEK cells stably expressing mCB2 and hCB2. (A) In HEK cells stably expressing mCB2, AM1710 increased phosphorylation of JNK $46 / 54$ at 5 and 10 minutes, and CP55940 increased phosphorylation of JNK 46/54 only at 5 minutes. (B) In HEK cells stably expressing hCB2, AM1710 increased phosphorylation of JNK 46/54 at 5 minutes, and CP55940 increased phosphorylation of JNK 46/54 at 5 and 10 minutes. ${ }^{*} P<0.05$ vs. vehicle; ${ }^{\#} P<0.05$ significant difference between CP55940 and AM1710. AU, arbitrary unit. $n=3$ for each group. changed over time $\left(F_{4,32}=18.86, P<0.001\right)$ (Fig. 3A). Both CP55940 and AM1710 increased JNK 46/54 phosphorylation $\left(F_{3,8}=17.4, P<0.001\right)$, and this effect was time-dependent $\left(F_{12,32}=7.813, P<0.001\right)$ (Fig. 3A). Specifically, AM1710 increased JNK $46 / 54$ phosphorylation at $5(P<0.001)$ and 10 minutes $(P<0.001)$, whereas CP55940 activated JNK 46/ 54 phosphorylation at 5 minutes $(P=0.002)$ (Fig. 3A). No differences were observed between vehicle and basal conditions $(P>0.266$ ) (Fig. 3A). Similarly, both CP55940 and AM1710 activated the phosphorylation of JNK 46/54 in HEK cells stably expressing hCB2 $\left[F_{12,32}=7.813, P<0.001\right.$ (treatment); $F_{12,32}=7.813, P<0.001$ (time); $F_{12,32}=7.813$, $P<0.001$ (interaction)] (Fig. 3B). AM1710 increased JNK 46/54 phosphorylation at $5(P=0.001)$, and CP55940 activated JNK $46 / 54$ phosphorylation at $5(P<0.001)$ and 10 minutes $(P=$ 0.002). No differences were observed between vehicle and basal conditions $(P>0.357)$ (Fig. 3B).

History of Chronic AM1710 Treatment Suppresses Paclitaxel-Induced Allodynia and Delays the Development of Tolerance to the Antiallodynic Effects of Morphine. Paclitaxel (4 mg/kg, i.p.), administered on four alternate days, induced neuropathic pain in mice, as indicated by the reduction in the mechanical withdrawal threshold $\left(F_{1,21}=544.316, P<0.001\right)$ (Fig. 4A) and increase in the response time to cold stimulation $\left(F_{1,21}=204.137, P<0.001\right)$ (Fig. 4B). No group difference was observed $\left[F_{2,21}=0.644\right.$, $P=0.535$ (mechanical); $F_{2,21}=0.284, P=0.755$ (cold)] in mechanical or cold responsiveness before pharmacologic manipulations. An interaction between paclitaxel treatment and groups was detected for mechanical paw withdrawal threshold $\left(F_{2,21}=4.463, P=0.024\right)$, although Bonferroni post hoc tests failed to detect any significant pairwise comparisons, suggesting that mechanical paw withdrawal thresholds did not differ between groups before phase I dosing. The interaction between chemotherapy treatment and groups for cold sensitivity was not significant $\left(F_{2,21}=1.489, P=0.248\right)$. Thus, groups were similar before initiation of drug treatments.

To study the effects of AM1710 pretreatment on the development of tolerance to morphine, pharmacologic manipulations were used in two phases of treatment during the maintenance of neuropathic pain, when neuropathic pain was established and stable. AM1710 (5 mg/kg per day i.p. $\times$ 12 days), administered once daily for 12 consecutive days to paclitaxel-treated WT mice during phase I, increased mechanical paw withdrawal thresholds $\left(F_{2,21}=74.940\right.$, $P<0.001$ ) (Fig. 4A) and reduced the heightened cold response time $\left(F_{2,21}=52.339, P=0.001\right)$ (Fig. $\left.4 \mathrm{~B}\right)$ compared with the vehicle treatment. Mechanical and cold sensitivity returned to the baseline level measured before paclitaxel injection $[P=$ 0.521 (mechanical), $P=0.374$ (cold); planned comparison between baseline 1 and day 1 of phase I, paired $t$ test]. The antiallodynic effect of AM1710 did not differ as a function of time $\left[F_{6,63}=1.176, P=0.33\right.$ (mechanical); $F_{6} 63=1.301$, $P=0.270$ (cold)]. Mechanical paw withdrawal thresholds $\left(F_{3,63}=3.329, P=0.025\right.$, Bonferroni post hoc test did not reveal any differences $)$ and cold response times $\left(F_{3,63}=1.189\right.$, $P=0.321$ ) remained stable throughout phase I treatment, indicating that tolerance did not develop to the antiallodynic effects of AM1710 over repeated administration for either stimulus modality (Fig. 4).

On day 15, 3 days after the completion of phase I of AM1710 treatment, mechanical and cold hypersensitivity returned to the level of hypersensitivity detected before AM1710 treatment $[P=0.230$ (mechanical), $P=0.630$ (cold); planned comparison between baseline 2 (BL2) and Pac in Fig. 4, paired $t$ test). Chronic administration of morphine $(10 \mathrm{mg} / \mathrm{kg}$ per day i.p. $\times 12$ days) was then initiated in phase II on day 16 . Overall, repeated morphine dosing in phase II reduced mechanical $\left(F_{3,60}=53.59, P<0.001\right)$ and cold $\left(F_{3,60}=32.45, P<\right.$ 0.001 ) responsiveness in paclitaxel-treated mice, but mechanical paw withdrawal thresholds $\left(F_{2,20}=19.746, P<0.001\right)$ and cold response times $\left(F_{2,20}=11.049, P=0.001\right)$ differed between groups. Mechanical and cold sensitivity in each group varied differently over repeated morphine administration $\left[F_{6,60}=20.34, P<0.001\right.$ (mechanical); $F_{6,60}=15.271$, $P<0.001$ (cold)]. Specifically, morphine reduced mechanical $(P<0.001)$ and cold $(P<0.001)$ responsiveness in paclitaxeltreated mice relative to the vehicle group on the first day (day 16) of morphine treatment (Fig. 4). By day 19, however, morphine was no longer efficacious in reducing paclitaxelinduced hypersensitivities in vehicle (I)-morphine (II)-treated groups, consistent with the development of morphine tolerance (Fig. 4). By contrast, morphine suppressed responsiveness to both modalities of cutaneous stimulation $(P<0.001$ mechanical; $P=0.015$ cold) on day 19 in paclitaxel-treated mice that received AM1710 (I)-morphine (II) treatment, although efficacy disappeared by day 23 (Fig. 4). These results indicate that a history of AM1710 treatment delayed the development of tolerance to morphine.

Naloxone-Precipitated Opioid Withdrawal Was Decreased in Morphine-Tolerant Mice with a History of AM1710 Treatment. We also evaluated whether prior chronic treatment with AM1710 (5 mg/kg i.p. $\times 12$ days $)$ in phase I would impact naloxone-precipitated morphine withdrawal 

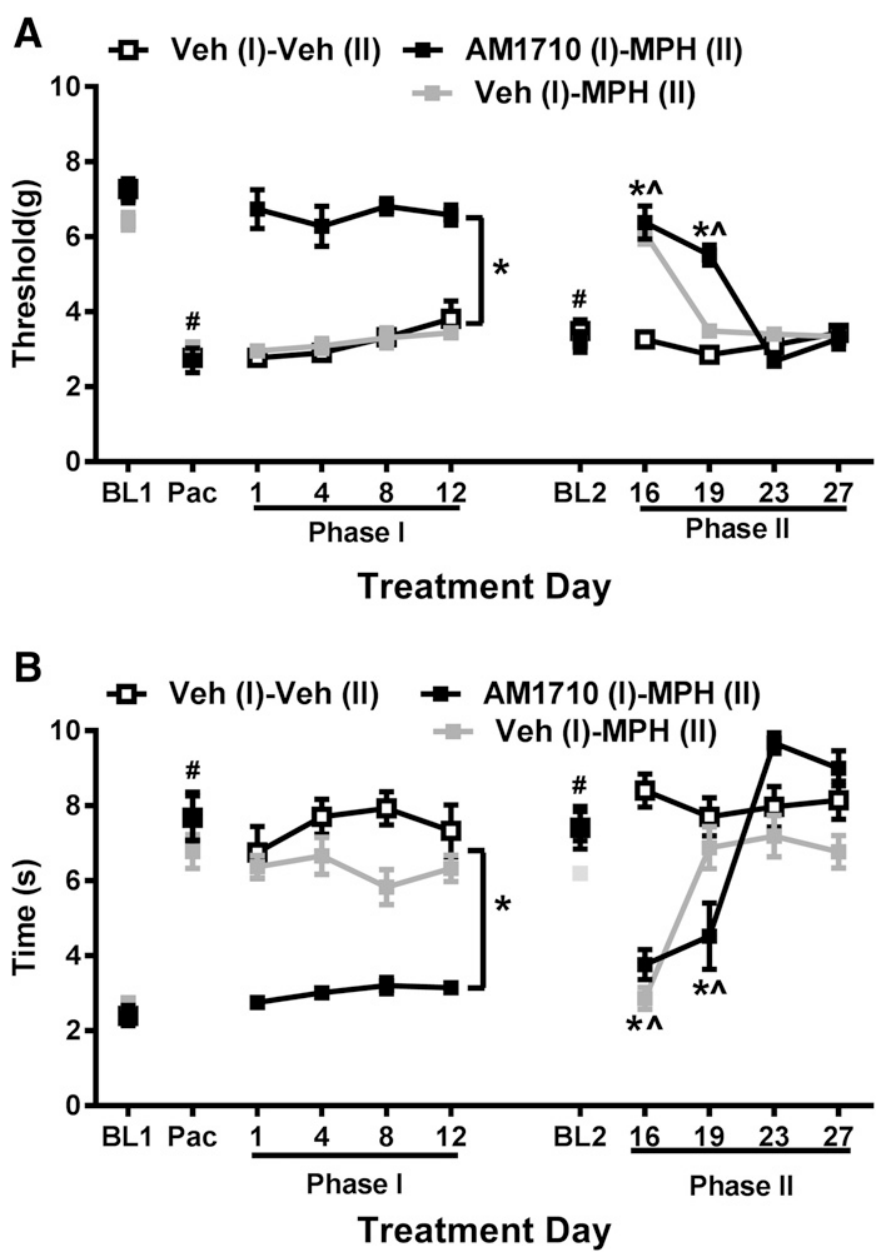

Fig. 4. AM1710 sustainably suppressed paclitaxel-induced allodynia and delayed the development of morphine antinociceptive tolerance in mice. C57BL/J6 mice received a total of four doses of paclitaxel ( $4 \mathrm{mg} / \mathrm{kg}$, i.p.) to develop peripheral neuropathic pain. After the paclitaxel-induced neuropathic pain was fully established, AM1710 $(5 \mathrm{mg} / \mathrm{kg}$ per day $\times 12$ days $)$ alone was administered during phase I, and 4 days after AM1710 administration, animals received chronic treatment of morphine $(10 \mathrm{mg} /$ $\mathrm{kg}$ per day $\times 12$ days) alone during phase II. AM1710 sustainably suppressed mechanical (A) and cold (B) allodynia induced by paclitaxel during phase I. The history of AM1710 treatment during phase I delayed the development of morphine tolerance in phase II, $n=8$ males, C57BL/6J for each group. ${ }^{\#} P<0.05$ vs. BL (baseline); ${ }^{*} P<0.05$ vs. veh (I) - veh (II); ${ }^{\wedge} P<0.05$ vs. day 23 (two-way mixed ANOVA, followed by Bonferroni post hoc test). BL, baseline; MPH, morphine; veh, vehicle.

symptoms in mice rendered tolerant to morphine $(10 \mathrm{mg} / \mathrm{kg}$ i.p. $\times 12$ days) in phase II. The number of naloxoneprecipitated jumps differed reliably between groups $\left(F_{2,19}=\right.$ $7.264, P=0.0045$; one-way ANOVA). Paclitaxel-treated mice that received vehicle (I)-morphine (II) treatment exhibited a greater number of jumps compared with vehicle (I)-vehicle (II)-treated mice that never received morphine $(P=0.002$; Bonferroni post hoc test) (Fig. 5A). Moreover, naloxoneprecipitated jumps did not differ between the AM1710 pretreatment [i.e., AM1710 (I)-morphine (II)] and vehicle [i.e., vehicle (I)-vehicle (II)) groups $(P=0.188$; Bonferroni post hoc test] (Fig. 5A). The number of naloxone-precipitated jumps was lower in the AM1710 (I)-morphine (II)) group compared with the vehicle (I)-morphine (II) group that received identical morphine treatments $(P=0.042$; Bonferroni multiple comparison test). These observations suggest that AM1710
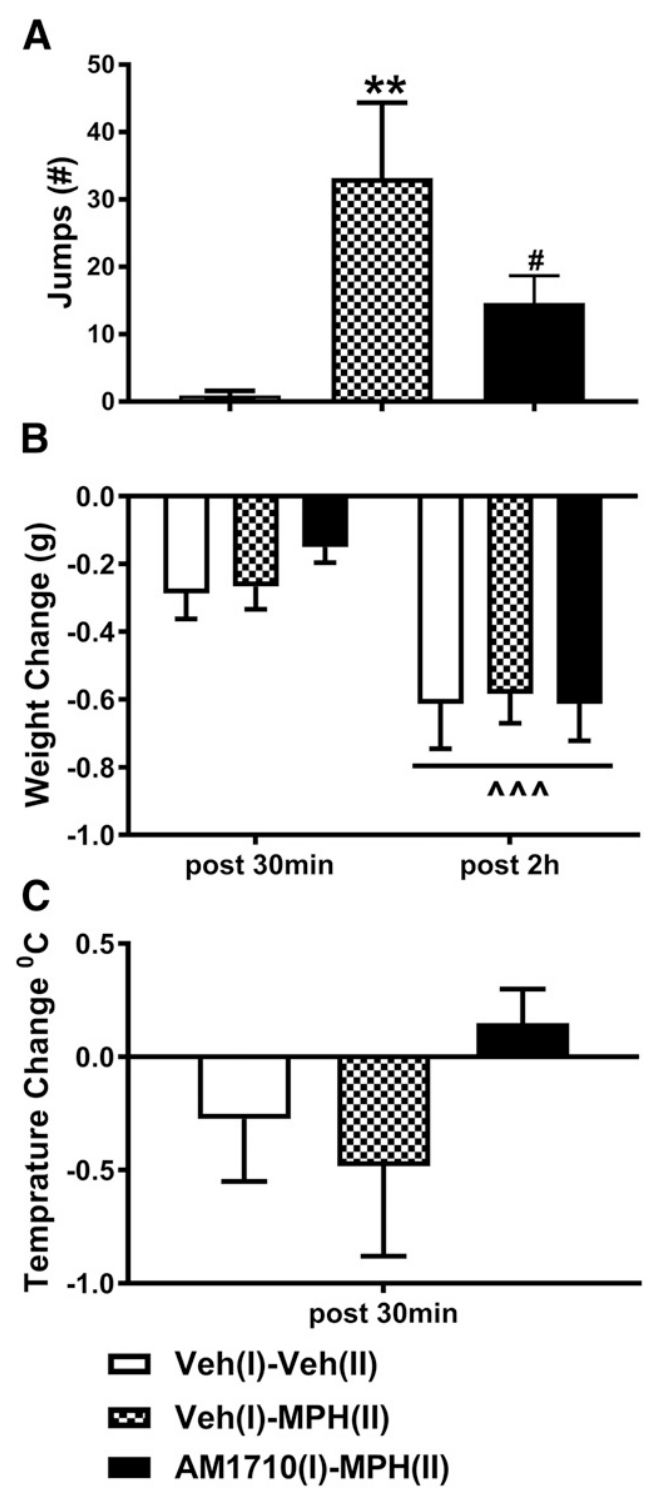

Fig. 5. AM1710 attenuates naloxone-precipitated opioid withdrawal Paclitaxel-treated mice rendered tolerant to morphine were challenged with naloxone (5 mg/kg, i.p.) to induce physical withdrawal. (A) Animals pretreated with AM1710 (5 mg/kg per day $\times 12$ days, i.p.) before morphine (MPH) treatment $(10 \mathrm{mg} / \mathrm{kg}$, i.p.) for 12 days exhibited less jumping behavior compared with animals receiving morphine alone. (B) Weight loss did not differ among treatments. (C) Body temperature changes did not differ among treatments. $n=8$ males, C57BL/6J for each group., $* * P<0.01$ vs. veh (I)-veh (II) (one-way ANOVA, followed by Bonferroni post hoc test); ${ }^{\#} P<0.05$ vs. vehicle (I)-morphine (II) (one-way ANOVA, followed by Bonferroni multiple comparison test). ${ }^{\wedge} \wedge P P<0.001$ vs. post 30 minutes (two-way mixed ANOVA) veh, vehicle; MPH, morphine.

attenuated naloxone-precipitated withdrawal jumps in morphine-dependent mice, and that withdrawal jumping was normalized by AM1710 pretreatment.

AM1710 did not alter the effects of naloxone challenge on body weight or body temperature. Body weight decreased over time after naloxone injection $\left(F_{1,19}=36.052, P<0.001\right)$, which was independent of the treatment $\left(F_{2,19}=0.626, P=\right.$ $0.546)$, and weight loss did not differ among treatments $\left(F_{2,19}\right.$ $=0.219, P=0.806$ ) (Fig. 5B). Similarly, no differences were observed between treatments with respect to changes in body temperature induced by naloxone challenge $\left(F_{2,21}=1.390\right.$, $P=0.273$ ) (Fig. 5C). 
AM1710 Does Not Precipitate Cannabinoid CB1 Receptor-Mediated Withdrawal. In mice chronically treated with $\Delta^{9}$-THC $(50 \mathrm{mg} / \mathrm{kg}$ per day i.p. $\times 9$ days $)$, pharmacologic challenge (second challenge) increased the number of each withdrawal parameter relative to the earlier vehicle challenge (first challenge) of the same mice $\left[F_{1,10}=\right.$ $15.093, P=0.003$ (paw tremor); $F_{1,10}=5.729, P=0.038$ (headshakes); $F_{1,10}=10.07, P=0.01$ (grooming); $F_{1,10}=$ $14.259, P=0.004$ (rearing)] (Fig. 6). Challenge with the CB1 antagonist rimonabant elicited more withdrawal behaviors than challenge with AM1710 $\left[F_{1,10}=16.426, P=0.002\right.$ (paw tremor); $F_{1,10}=8.13, P=0.017$ (headshakes) $F_{1,10}=19.659$, $P=0.001$ (grooming); $F_{1,10}=19.552, P=0.001$ (rearing)], and this effect was phase-dependent $\left[F_{1,10}=15.910, P=0.003\right.$ (paw tremor); $F_{1,10}=9.027, P=0.013$ (headshakes); $F_{1,10}=$ $6.224, P=0.032$ (grooming); $F_{1,10}=16.821, P=0.002$ (rearing)]. Bonferroni post hoc tests revealed no difference in the withdrawal behaviors after early vehicle challenge, but later rimonabant challenge induced greater numbers of each withdrawal behavior relative to AM1710 challenge $(P<0.05)$ (Fig. 6). Moreover, rimonabant challenge produced more withdrawal behaviors compared with the early vehicle challenge of the same animals $(P<0.01)$ (Fig. 6$)$. By contrast, AM1710 challenge did not elicit more withdrawal behaviors compared with the earlier vehicle challenge in the same animals $(P>0.05)$, indicating that AM1710 at $10 \mathrm{mg} / \mathrm{kg}$ did not precipitate CB1-receptor-mediated withdrawal (Fig. 6).

AM1710 Does Not Suppress Mechanical Allodynia in Mice in the CFA Model. Both WT and CB2 KO mice developed mechanical hypersensitivity after intradermal CFA injection as indicated by the observed reduction of the mechanical paw withdrawal threshold $\left(F_{1,14}=175.769\right.$,
$P<0.001$ ) (Fig. 7A). The degree of reduction in mechanical withdrawal threshold induced by CFA was similar in WT and CB2 KO mice $\left(F_{1,14}=0.012, P=0.915\right)$, and no interaction between group and CFA injection was observed $\left(F_{1,4}=0.888\right.$, $P=0.362$ ). After the establishment of CFA-induced inflammatory pain, doses of $\operatorname{AM} 1710(0,1,3,10 \mathrm{mg} / \mathrm{kg}$, i.p. ) that reversed paclitaxel-induced neuropathic pain (Deng et al., 2015b; see also, Fig. 4) did not reverse CFA-induced mechanical hypersensitivity $\left(F_{3,42}=2.165, P=0.106\right)$. The lack of antiallodynic efficacy of AM1710 was observed in both WT and CB2 KO mice $\left(F_{1,14}=0.834, P=0.376\right)$, and the interaction between the dose of AM1710 and the genotype was not significant $\left(F_{3,42}=1.344, P=0.273\right)$. By contrast, the positive control gabapentin reversed CFA-induced mechanical hypersensitivity relative to the vehicle treatment in WT mice, as shown in Fig. 7B $\left[F_{3,30}=19.009, P<0.001\right.$ (dose); $F_{1,10}=$ $9.210, P=0.01$ (group); $F_{3,30}=4.168, P=0.014$ (interaction)]. The gabapentin-induced reversal of mechanical hypersensitivity was dose-dependent as revealed by Bonferroni post hoc tests. Specifically, gabapentin at a dose of 30 and $100 \mathrm{mg} / \mathrm{kg}$ increased mechanical withdrawal thresholds compared with the vehicle group $(P<0.01)$ and compared with the lower doses of 3 and $10 \mathrm{mg} / \mathrm{kg}(P<0.05)$.

We further investigated the effect of prophylactic chronic treatment with AM1710 (10 mg/kg per day $\times 12$ days, i.p. $)$ on CFA-induced mechanical allodynia in WT mice. Chronic AM1710 treatment was initiated 30 minutes before the CFA injection on day 1 and continued once daily for 12 consecutive days (i.e., until day 12). Pre-emptive AM1710 treatment before CFA injection did not prevent the development of mechanical allodynia induced by CFA as the mechanical threshold declined 24 hours after the CFA injection on day
A
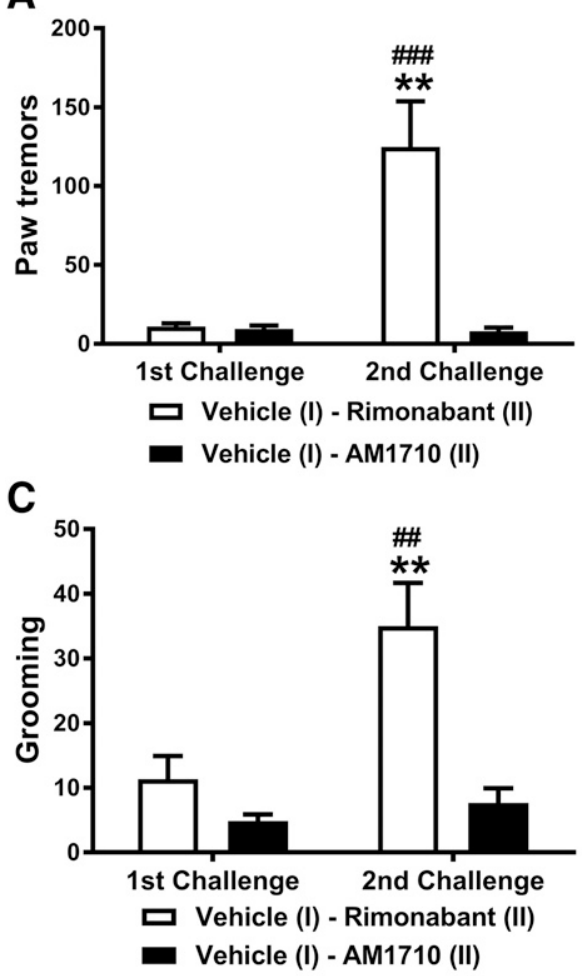

B

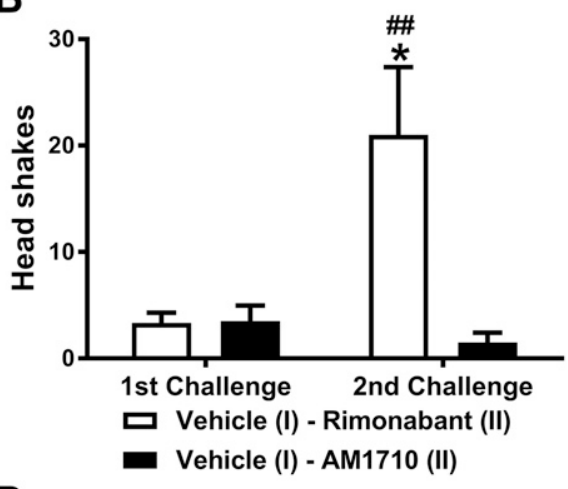

D

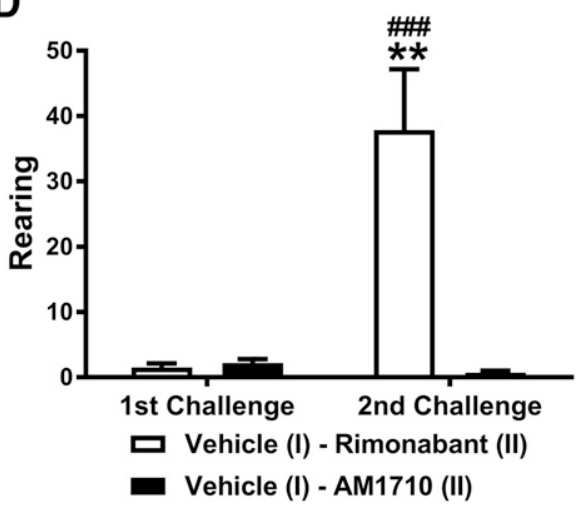

Fig. 6. AM1710 does not precipitate CB1 receptor-mediated cannabinoid withdrawal. Administration of the CB1 antagonist rimonabant $(10 \mathrm{mg} / \mathrm{kg}$, i.p.) increased the number of paw tremors (A), headshakes (B), grooming (C), and rearing behaviors (D) in mice chronically treated with $\Delta^{9}$-THC $(50 \mathrm{mg} / \mathrm{kg}$ per day $\times 9$ days, i.p.). By contrast, AM1710 $(10 \mathrm{mg} / \mathrm{kg}$, i.p.) did not induce these CB1 receptor-mediated withdrawal behaviors. $n=6$ males, C57BL/6J for each group. ${ }^{\# \#} P<0.01$; ${ }^{\# \# \#} P<0.001$ vs. vehicle; ${ }^{*} P<$ $0.05 ; * * P<0.01$ vs. AM1710 (two-way mixed ANOVA, followed by Bonferroni post hoc test). First challenge: vehicle challenge; second challenge: rimonabant or AM1710 challenge. 

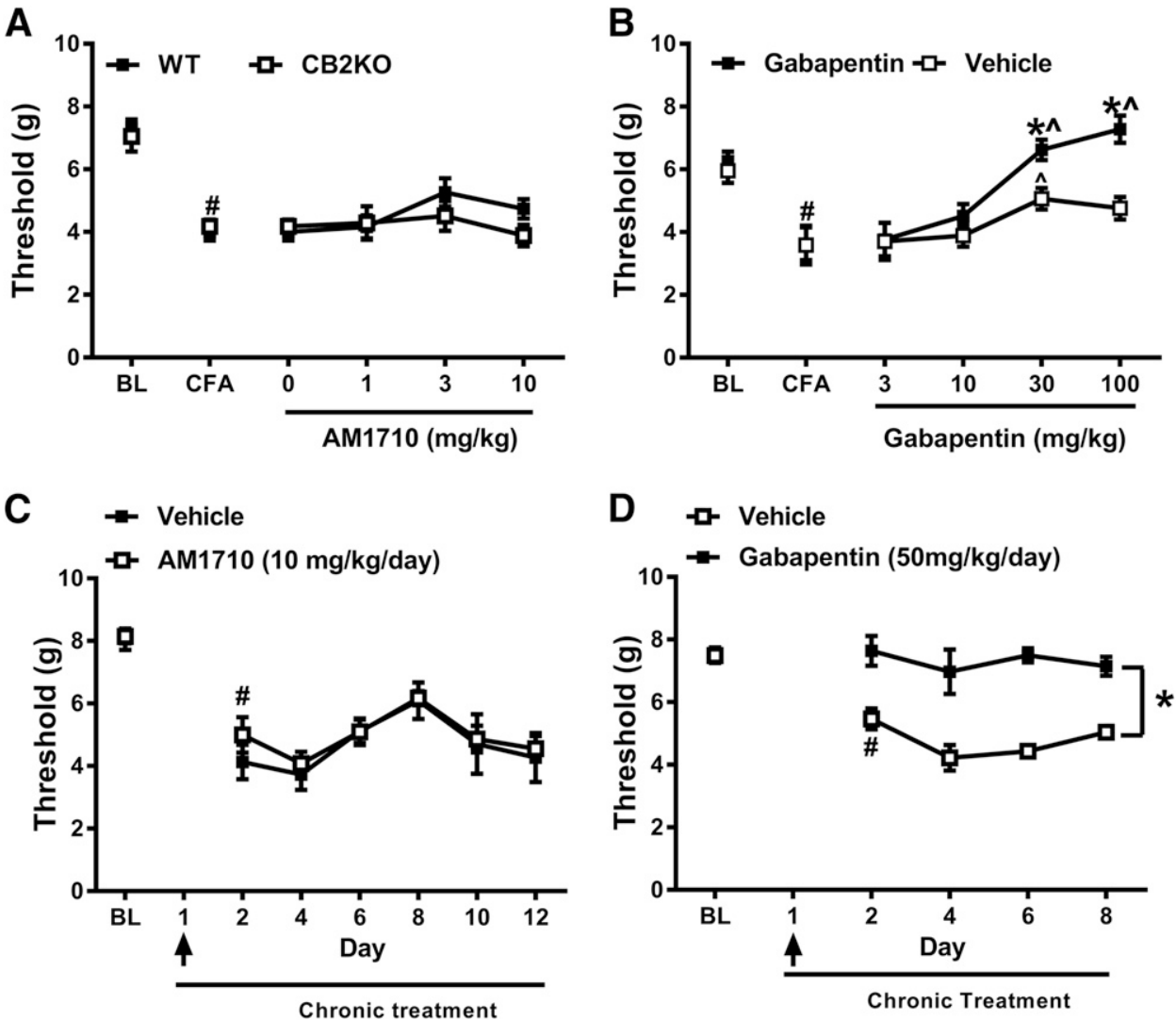

Fig. 7. AM1710 does not suppress mechanical allodynia induced by CFA injection. (A) Increasing doses of AM1710 (0-10 mg/kg, i.p.) did not reverse CFAinduced mechanical allodynia in either WT or CB2KO after inflammatory pain was fully established (mixed sex, $n=$ $8 \mathrm{C} 57 \mathrm{BL} / 6 \mathrm{~J}$ for WT, $n=8 \mathrm{CB} 2 \mathrm{KO}$ ). (B) Gabapentin (30 and $100 \mathrm{mg} / \mathrm{kg}$, i.p.) suppressed mechanical allodynia in WT mice after CFA-induced inflammatory pain was established ( $n=6$ males, C57BL/6J for each group). (C) Prophylactic and chronic treatment of AM1710 starting 30 minutes before CFA injection and continuing up to day 12 did not prevent or suppress mechanical allodynia induced by CFA in WT. $(n=$ 6 males, C57BL/6J for AM1710 group; $n=$ 5 males, C57BL/6J for vehicle group). (D) Prophylactic and chronic treatment of gabapentin starting 30 minutes before CFA injection and continuing up to day 8 prevented and sustainably suppressed mechanical allodynia induced by CFA in WT. ( $n=6$ males, C57BL/6J for each group). ${ }^{\#} P<0.05$ vs. BL (baseline); ${ }^{*} P<$ 0.05 vs. vehicle; $\wedge^{\wedge} P<0.05$ vs. gabapentin $3 \mathrm{mg} / \mathrm{kg}$ (two-way mixed ANOVA, followed by Bonferroni post hoc test). Black arrow indicates the day when AM1710 $(10 \mathrm{mg} / \mathrm{kg}$, i.p.) or gabapentin $(50 \mathrm{mg} / \mathrm{kg}$, i.p.) was injected 30 minutes before the CFA injection. WT, wild- type.

$2\left(F_{1,9}=75.709, P<0.001\right)$, independent of the treatment $\left(F_{1,9}=0.911, P=0.365\right)$, and mechanical thresholds did not differ between groups $\left(F_{1,9}=1.013, P=0.340\right)$. During the subsequent chronic treatment with AM1710 (i.e., day 2-day 12), mechanical paw withdrawal thresholds varied over time $\left(F_{5,45}=4.892, P=0.001\right)$ independent of the treatment $\left(F_{5,45}=\right.$ $0.209, P=0.957)$, but mechanical responsiveness did not differ between the AM1710 and vehicle-treated groups $\left(F_{1,9}=\right.$ $0.482, P=0.505$ ) (Fig. 7C), suggesting a lack of antiallodynic efficacy of AM1710. By contrast, gabapentin treatment 30 minutes before CFA injection successfully prevented the development of mechanical allodynia induced by CFA; mechanical paw withdrawal thresholds were reduced on day 2 in the vehicle-treated mice $(P=0.001)$ but not in gabapentintreated mice $(P=0.810)$. Mechanical paw withdrawal thresholds changed over time during subsequent gabapentin chronic treatment from day 2 to day $8\left(F_{3,30}=3.168, P=0.039\right)$, but post hoc comparisons did not reveal any significant differences across days. The observation of group differences in CFAinduced mechanical sensitivity $\left(F_{1,10}=40.718, P<0.001\right)$ between vehicle- and gabapentin-treated groups were independent of time $\left(F_{3,30}=1.081, P=0.372\right)$, which implies a sustained gabapentin-induced suppression of CFA-induced mechanical hypersensitivity throughout the testing period compared with the vehicle group (Fig. 7D).

AM1710 Does Not Suppress Mechanical or Cold Allodynia in the PSNL Model. PSNL decreased mechanical paw withdrawal thresholds $\left(F_{1,10}=27.434, P<0.001\right)$ in a manner independent of the genotype $\left(F_{1,10}=1.437, P=0.258\right)$ (Fig. 8A), and neuropathic pain developed similarly in WT and $\mathrm{CB} 2 \mathrm{KO}$ mice $\left(F_{1,10}=0.000253, P=0.988\right)$. After the establishment of PSNL-induced neuropathic pain, a main effect of AM1710 treatment was detected $(0,1,3,10 \mathrm{mg} / \mathrm{kg}$, i.p.) $\left(F_{3,30}=3.487, P=0.028\right)$, but Bonferroni post hoc tests failed to reveal any differences between these doses. Moreover, no difference in responsiveness was detected between $\mathrm{WT}$ and $\mathrm{CB} 2 \mathrm{KO}$ mice $\left(F_{1,10}=0.001, P=0.975\right)$, and responsiveness was independent of the doses $\left(F_{3,30}=1.129\right.$, $P=0.353$ ), suggesting a lack of antinociceptive efficacy of AM1710 in the PSNL model. By contrast, in WT mice, gabapentin increased mechanical paw withdrawal thresholds relative to the vehicle group (Fig. $8 \mathrm{~B}$ ) $\left[F_{3,30}=15.420\right.$, $P<0.001$ (dose; $F_{1,10}=24.134, P=0.001$ (group); $F_{3,30}=$ $10.996, P<0.001$ (interaction)]. Gabapentin produced significant reversal of mechanical allodynia at doses of 30 and $50 \mathrm{mg} / \mathrm{kg}$ compared with either the vehicle group $(P<0.001)$ or lower doses of gabapentin (i.e., 3 and $10 \mathrm{mg} / \mathrm{kg}$ i.p.; $P<$ 0.05) (Fig. 8B).

CP55940 Does Not Suppress Mechanical or Cold Allodynia in CB1KOs in CFA or PSNL Models. Because of the lack of robust antiallodynic efficacy of AM1710 in PSNL and CFA models, we asked whether CB2-mediated antiallodynic effects could be observed in these two models using a different, functionally balanced cannabinoid agonist, CP55940. In AtT20 cells expressing mCB2, CP55940 inhibits voltage-gated calcium channels, whereas AM1710 fails to do so (Atwood et al., 2012; Dhopeshwarkar and Mackie, 2016). Both CP55940 and AM1710 inhibit cyclase and recruit arrestin with similar efficacy (Dhopeshwarkar and Mackie, 2016). Consequently, we evaluated the antiallodynic effect of CP55940 using CB1 KO mice to eliminate unwanted motor effects associated with activation of CB1 that would otherwise 
A

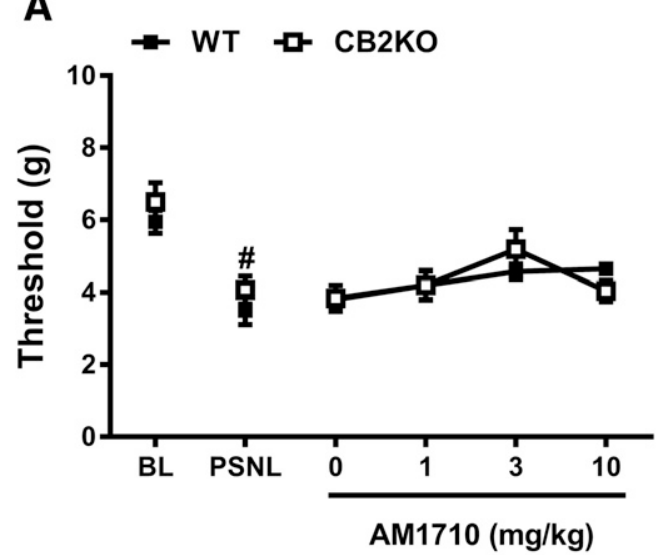

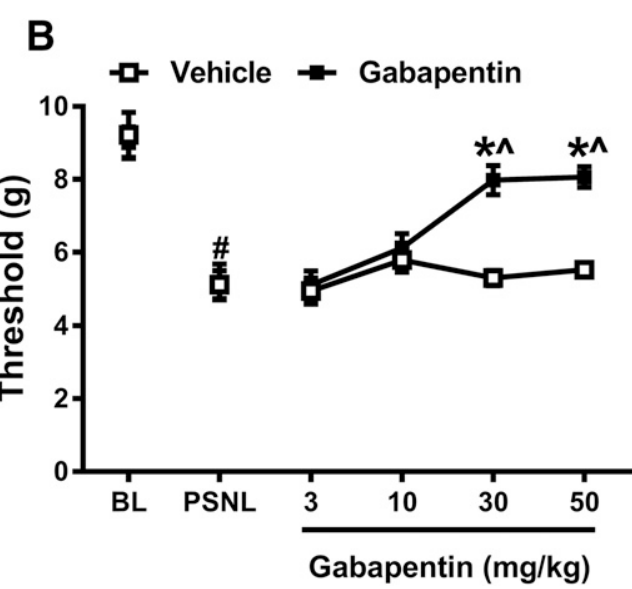

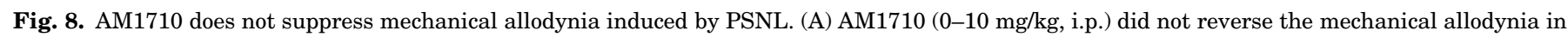

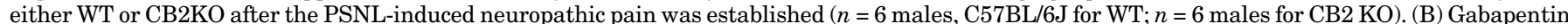

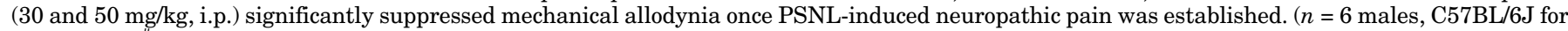

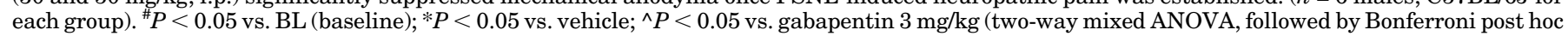
test). BL, baseline.

mask detection of CB2-mediated antiallodynic effects (Deng et al., 2015a).

Intradermal CFA injection lowered mechanical paw withdrawal thresholds in CB1 KO mice $\left(F_{1,5}=97.925, P<0.001\right)$ in a manner that was selective for the CFA-injected (ipsilateral) paw $\left(F_{1,5}=12.915, P=0.016\right)$. As expected, mechanical paw withdrawal thresholds were lower in the ipsilateral compared with contralateral $\left(F_{1,5}=25.457, P=0.004\right)$ paw. Intraplantar injection of CFA decreased the mechanical paw withdrawal threshold in the ipsilateral paw of CB1 KO mice $(P<0.001)$ but did not alter responding in the noninflamed (contralateral) paw $(P=0.512)$ (Fig. 9A). CP55940, at increasing doses $(0,3,10 \mathrm{mg} / \mathrm{kg}$, i.p.), was not able to reverse CFA-induced mechanical hypersensitivity $\left(F_{2,10}=1.209, P=\right.$ 0.339). Moreover, mechanical paw withdrawal thresholds were lower in the ipsilateral compared with the contralateral paw of the same mice $\left(F_{1,5}=335.290, P<0.001\right)$, and this effect was independent of the dose of CP55940 $\left(F_{2,10}=0.288\right.$, $P=0.756)$. Thus, CP55940 did not alleviate the CFA-induced allodynia in CB1 KO mice (Fig. 9A).

PSNL decreased mechanical paw withdrawal thresholds $\left(F_{1,6}=54.17, P<0.001\right)($ Fig. 9B) and increased cold response durations $\left(F_{1,6}=20.747, P=0.004\right)$ (Fig. 9C) in CB1 KO mice. The changes in mechanical and cold sensitivity were selective for the paw ipsilateral to traumatic nerve injury $\left[F_{1,6}=\right.$ 307.932, $P<0.001$ (mechanical); $F_{1,6}=15.469, P=0.008$ (cold)]. Mechanical paw withdrawal threshold and cold responsiveness were lower in the ipsilateral compared with the contralateral paw $\left[F_{1,6}=35.828, P=0.001\right.$ (mechanical); $F_{1,6}=20.148, P=0.004$ (cold)] (Fig. 9, B and C). PSNL surgery lowered mechanical paw withdrawal threshold $(P<0.001)$ and increased cold sensitivity $(P<0.001)$ in the ipsilateral (i.e., injured) paw without altering responsiveness in the contralateral (uninjured) paw $[P=0.330$ (mechanical), $P=$ 0.325 (cold)] (Fig. 9, B and C). CP55940 (0, 3, $10 \mathrm{mg} / \mathrm{kg}$, i.p.) did not produce a robust antiallodynic efficacy in mice subjected to PSNL $\left[F_{2,12}=2.147, P=0.160\right.$ (mechanical); $F_{2,12}=0.375$, $P=0.695$ (cold)]. Mechanical paw withdrawal thresholds $\left(F_{1,6}=110.775, P<0.001\right)$ were lower, and cold sensitivity $\left(F_{1,6}=41.852, P=0.001\right)$ was greater in the ipsilateral side compared with the contralateral side, and these responses were not impacted by CP55940 dose $\left[F_{2,12}=1.528, P=0.256\right.$ (mechanical); $F_{2,12}=0.383, P=0.690$ (cold)] (Fig. 9, B and C), indicating lack of antiallodynic efficacy of CP55940 in PSNL of CB1 KO mice.

\section{Discussion}

Opioid tolerance and physical dependence limit clinical use for treating chronic pain (Volkow et al., 2018). Here we show that chronic pretreatment with the CB2 agonist AM1710 delayed, but did not eliminate, the development of morphine tolerance in paclitaxel-treated mice. These observations correspond with the ability of the G protein-biased CB2 agonist LY2828360 to block development of antinociceptive tolerance to morphine in paclitaxel-treated WT but not CB2 KO mice (Lin et al., 2017). Antiallodynic effects of AM1710 are absent in CB2 KO and preserved in CB1 KO mice (Deng et al., 2015b), validating its use as a CB2 agonist in the present studies. In HEK cells expressing mCB2, both AM1710 (present study) and LY2828360 (Lin et al., 2017) inhibit adenylyl cyclase and activate ERK1/2, albeit with different time courses; however, LY2828360 does not internalize CB2 receptors or recruit $\beta$-arrestin (Lin et al., 2017), in contrast to AM1710 (Atwood et al., 2012; Dhopeshwarkar and Mackie, 2016). CB2 agonists may diminish morphine tolerance to different degrees, depending on the agonist and its signaling profile, although mediation by CB2 has not been consistently assessed. In tumor-bearing rats, the CB2 agonist AM1241 blocked morphine analgesic tolerance in the hotplate test, but not in assessments of mechanical allodynia (Zhang et al., 2016). JWH-015 (2-methyl-1propyl- 1H-indol-3-yl)-1-naphthalenylmethanone potentiated morphine antinociception and antinociceptive tolerance, although mediation by CB2 was not assessed (Altun et al., 2015). By contrast, the putative CB2 antagonist JTE-907 (N(benzo[1,3] dioxol-5-ylmethyl)-7-methoxy-2-oxo-8-pentyloxy1,2-dihydroquinoline-3-carboxamide) reduced morphine's antinociceptive efficacy and tolerance (Altun et al., 2015). Different agonists, pain states, and/or off-target effects could account for differences between studies. 


\section{CB1 KO}
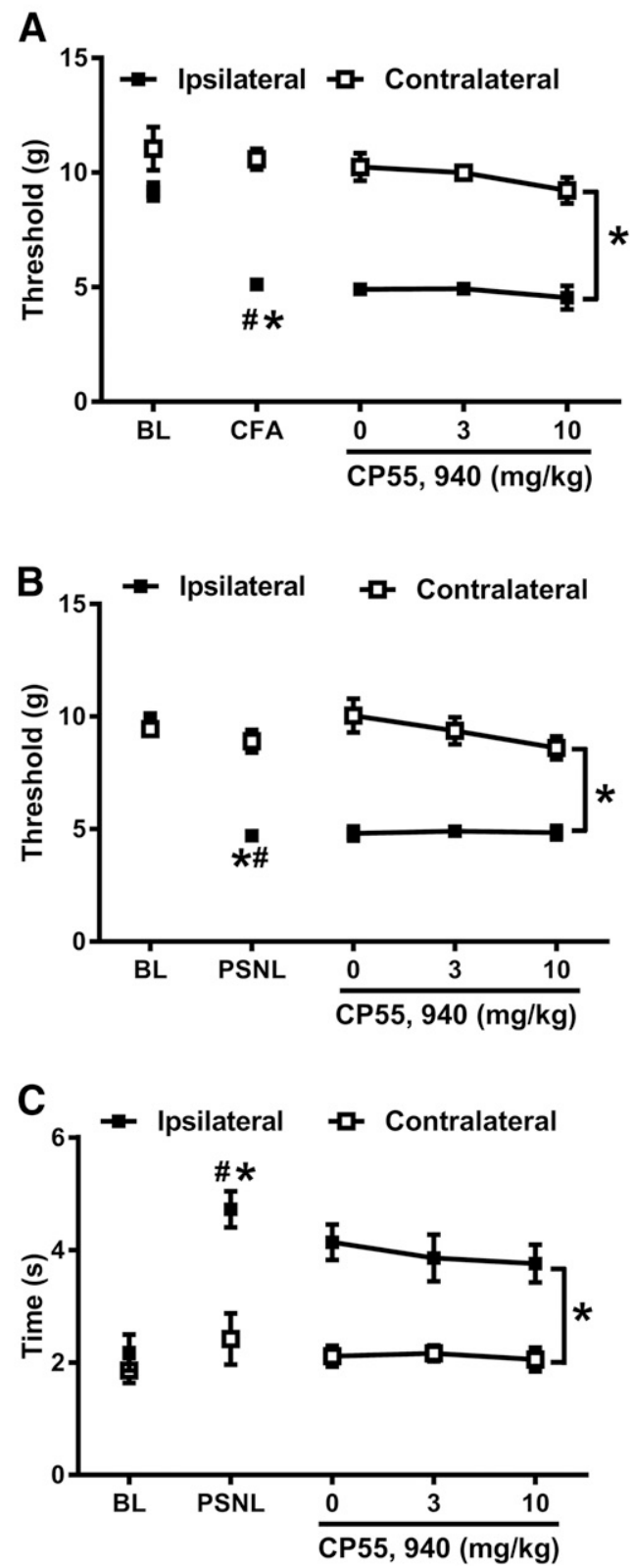

Fig. 9. CP55940 does not suppress allodynia induced by CFA or PSNL in CB1 KO. (A) CP55940 (0-10 mg/kg, i.p.) did not suppress mechanical allodynia induced by CFA. ( $n=6$ males, CB1 KO) (B) Different doses of CP55940 (0-10 mg/kg, i.p.) did not suppress mechanical allodynia induced by PSNL. ( $n=7$ males, CB1 KO). (C) Different doses of CP55940 (0-10 mg/kg, i.p.) did not suppress cold allodynia induced by PSNL. ( $n=7$ males, CB1 KO). ${ }^{\#} P<0.05$ vs. BL (baseline); ${ }^{*} P<0.05$ vs. contralateral side (uninjured side). Two-way repeated measures ANOVA, followed by Bonferroni's post hoc test.

Morphine-induced glial activation and release of proinflammatory factors that oppose morphine antinociception may contribute to morphine tolerance; conversely, inhibition of glial activation or proinflammatory cytokine actions reduces morphine analgesic tolerance (for review, see Watkins et al., $2005,2009)$. Interestingly, deletion of $\mu$-opioid receptor (MOR), which is absent in microglia, from nociceptors abrogates development of morphine tolerance without disrupting analgesia (Corder et al., 2017). CB2 antibodies are not sufficiently robust to be used for immunohistochemical localization. Nonetheless, CB2 mRNA is detected in microglia, and levels increase under pathologic conditions (reviewed in Guindon and Hohmann, 2008; Atwood and Mackie, 2010). Thus, microglial CB2 activation may counter-regulate morphine-induced glial activation and release of proinflammatory cytokines. The minimally selective cannabinoid agonist JWH-015 attenuated morphine-induced increases in microglial proinflammatory mediators, possibly via a CB2/ Akt-ERK1/2 signaling pathway (Merighi et al., 2012). Antiinflammatory signaling via CB2 in immune cells (Galiegue et al., 1995) could oppose morphine tolerance by decreasing proinflammatory mediators (Grace et al., 2015). In tumorbearing rats, AM1241 increased MOR expression in spinal cord and DRG (Zhang et al., 2016).

AM1710 suppressed naloxone-precipitated opioid withdrawal in paclitaxel-treated mice and normalized naloxoneprecipitated jumping to control levels. Similarly, LY2828360 (I)-morphine (II) treatment trended to reduce naloxoneprecipitated opioid withdrawal in our previous study (Lin et al., 2017). Upregulation of adenylyl cyclase has been linked to mechanisms of opioid dependence (Bohn et al., 2000). Thus, CB2-mediated inhibition of adenylyl cyclase by either AM1710 or LY2828360 may counteract morphineinduced adenylyl cyclase upregulation to attenuate morphine withdrawal.

In vitro, AM1710 exhibits higher affinity to CB2 compared with CB1 (Khanolkar et al., 2007) but is a low-potency inverse agonist/antagonist at CB1 (Dhopeshwarkar et al., 2017). Our observation that a CB1 antagonist-enhanced antiallodynic efficacy of a CB2 agonist (Rahn et al., 2008) fostered medicinal chemistry efforts that led to development of AM1710. CB1 antagonism could enhance the selectivity of mixed ligands that bind preferentially to CB2 over CB1 and limit CB1mediated side effects. Nonetheless, in $\Delta^{9}$-THC-tolerant mice, challenge with rimonabant, but not AM1710, precipitated cannabinoid CB1-dependent withdrawal. Thus, CB1 antagonism observed in vitro did not translate to functionally relevant $\mathrm{CB} 1$ antagonism in vivo.

In our study, AM1710 (1-10 mg/kg, i.p.) did not suppress allodynia induced by PSNL or CFA. Moreover, prophylactic chronic treatment with AM1710 did not attenuate development of CFA-induced mechanical allodynia. Thus, lack of efficacy of AM1710 cannot be attributed to different stages in development of inflammatory nociception. Nonetheless, AM1710 (5 mg/kg, i.p.) suppressed paclitaxel-induced allodynia without tolerance in the present study and in our previously work (Rahn et al., 2014; Deng et al., 2015b). CFA, PSNL, and paclitaxel produce mechanistically distinct pain states that may contribute to differences between studies. AM1710 attenuates neuropathic allodynia produced by mechanistically distinct chemotherapeutic agents (Deng et al., 2012) and produces CB2-mediated suppressions of paclitaxel-induced allodynia in both mice (Deng et al., 2015b) and rats (Deng et al., 2012; Rahn et al., 2014). In rats, intrathecal AM1710 reversed mechanical allodynia induced by chronic constriction injury or human immunodeficiency virus-1 glycoprotein 120 (Wilkerson et al., 2012), although mediation by CB2 was not assessed. As a microtubuleinterfering agent, paclitaxel activates the c-Jun N-terminal kinase/stress-activated protein kinase (JNK/SAPK) signaling pathway (Wang et al., 1998); however, there is no direct 
causal link between paclitaxel-induced activation of JNK and paclitaxel-induced peripheral neuropathic pain. In our studies, AM1710 induced phosphorylation of JNK 46/54 in HEK cells stably expressing mCB2 and hCB2. JNK may, consequently, be activated in different cells by paclitaxel and AM1710. Both acute AM1710 and chronic AM1710 treatment reduced mRNA levels of monocyte chemoattractant protein 1 and tumor necrosis factor- $\alpha$ (Deng et al., 2015b) in lumbar spinal cord of paclitaxel-treated mice. It is therefore plausible that the inhibitory effect of AM1710 on these proinflammatory cytokines may underlie its antiallodynic efficacy in the paclitaxel model.

Other putative CB2 agonists suggested to exhibit antiallodynic effects in CFA model are GW405833 (Li et al., 2017), AM1241 (Hsieh et al., 2011; Gao et al., 2016), A836339 (Yao et al., 2009; Hsieh et al., 2011), GW842166X (Giblin et al., 2007), and A-796260 (Yao et al., 2008); however, most studies have not thoroughly evaluated pharmacologic specificity in vivo. Strikingly, in our previously published work, the putative CB2 agonist GW405833, which did not produce cardinal signs of CB1 activation in the tetrad, suppressed mechanical allodynia in both CFA and PSNL model in mice, but these effects were mediated by CB1 and not CB2 mechanisms ( $\mathrm{Li}$ et al., 2017). The other ligands noted herein were evaluated in rats, and most studies did not evaluate mechanical allodynia. Interestingly, JWH133 shows antinociceptive efficacy in the PSNL model after intrathecal but not systemic (i.e., intraperitoneal) administration (Yamamoto et al., 2008). These observations led us to ask another question: to what extent is CB2-mediated antinociceptive efficacy observed in CFA and PSNL models in mice? Our laboratory previously showed that high doses of CP55940 (3-10 mg/kg, i.p.) produced sustained CB2-mediated suppression of paclitaxel-induced allodynia in CB1 KO mice; these antiallodynic effects were blocked by the CB2 antagonist AM630 (Deng et al., 2015a); however, CP55940 (3, 10 mg/kg, i.p.) did not suppress CFA or PSNL-induced mechanical allodynia in CB1 KO mice in the present study. These observations suggest a lack of involvement of CB2 receptors in modulating allodynia in the CFA and PSNL models in mice.

Modest differences in the signaling profile of AM1710 were observed between mCB2 and hCB2 for inhibition of cAMP and activation of ERK1/2. For example, AM1710 induced early and brief inhibition of cAMP levels by mCB2 but induced a delayed and long-lasting inhibition of cAMP levels by hCB2. In addition, the presence of AM1710 and CP55940 enhanced cAMP levels at 30 minutes compared with forskolin treatment alone. This observation was specific for $\mathrm{mCB} 2$, but the mechanism underlying this effect remains unknown. Moreover, AM1710 induced early and long-lasting of ERK1/2 phosphorylation by mCB2 but only transiently increased phosphorylated ERK1/2 by hCB2. Thus, caution must be exerted when translating in vivo results from mice to humans. The delayed elevation of pERK at 30 minutes in the PTXtreated cells is consistent with $\beta$-arrestin activity, which exhibits a slow onset and is also insensitive to PTX. By contrast, activation of JNK signaling by AM1710 was similar at $\mathrm{mCB} 2$ and hCB2. It is important to emphasize that AM1710 displays functional selectivity distinct from LY2828360. AM1710 internalized CB2 and recruited $\beta$-arrestin2 (Atwood et al., 2012; Dhopeshwarkar and Mackie, 2016), but it only weakly activated MAPK and did not inhibit voltage gated calcium channel (Atwood et al., 2012). By contrast, LY2828360 did not recruit arrestin and failed to internalize CB2 (Lin et al., 2017). In addition, LY2822360 exhibited a slower onset than AM1710 in inhibiting adenylyl cyclase (Lin et al., 2017). Differences in the signaling profiles of AM1710 and LY2828360 likely contribute to agonist differences in ability to inhibit development morphine tolerance.

In conclusion, AM1710 delayed the development of morphine tolerance in paclitaxel-treated mice and reduced naloxone-precipitated opioid withdrawal. AM1710 did not produce functionally relevant CB1 antagonism in vivo. AM1710 suppressed paclitaxel-induced mechanical and cold allodynia but failed to suppress mechanical allodynia induced by either CFA or PSNL. The balanced cannabinoid agonist CP55940 similarly failed to suppress allodynia in either the CFA or PSNL models in CB1 KO mice. Modest species differences were also detected in signaling of AM1710 at mouse and human CB2. These observations should be considered when selecting appropriate therapeutic indications for CB2 agonists for clinical translation.

\section{Authorship Contributions}

Participated in research design: Mackie, Hohmann.

Conducted experiments: Li, Lin, Dhopeshwarkar, Thomaz, Carey. Contributed new reagents or analytic tools: Liu, Nikas, Makriyannis.

Performed data analysis: Li, Lin, Thomaz, Carey, Hohmann.

Wrote or contributed to the writing of the manuscript: $\mathrm{Li}$, Lin, Dhopeshwarkar, Thomaz, Carey, Mackie, Hohmann.

\section{References}

Altun A, Yildirim K, Ozdemir E, Bagcivan I, Gursoy S, and Durmus N (2015) Attenuation of morphine antinociceptive tolerance by cannabinoid CB1 and CB2 receptor antagonists. J Physiol Sci 65:407-415.

Atwood BK and Mackie K (2010) CB2: a cannabinoid receptor with an identity crisis. Br J Pharmacol 160:467-479.

Atwood BK, Wager-Miller J, Haskins C, Straiker A, and Mackie K (2012) Functional selectivity in $\mathrm{CB}(2)$ cannabinoid receptor signaling and regulation: implications for the therapeutic potential of $\mathrm{CB}(2)$ ligands. Mol Pharmacol 81:250-263.

Beltramo M, Bernardini N, Bertorelli R, Campanella M, Nicolussi E, Fredduzzi S, and Reggiani A (2006) CB2 receptor-mediated antihyperalgesia: possible direct involvement of neural mechanisms. Eur J Neurosci 23:1530-1538.

Bingham B, Jones PG, Uveges AJ, Kotnis S, Lu P, Smith VA, Sun SC, Resnick L, Chlenov M, He Y, et al. (2007) Species-specific in vitro pharmacological effects of the cannabinoid receptor 2 (CB2) selective ligand AM1241 and its resolved enantiomers. Br J Pharmacol 151:1061-1070.

Bohn LM, Gainetdinov RR, Lin F-T, Lefkowitz RJ, and Caron MG (2000) $\mu$-opioid receptor desensitization by $\beta$-arrestin- 2 determines morphine tolerance but not dependence. Nature 408:720-723.

Brown SM, Wager-Miller J, and Mackie K (2002) Cloning and molecular characterization of the rat CB2 cannabinoid receptor. Biochim Biophys Acta 1576:255-264. Corder G, Tawfik VL, Wang D, Sypek EI, Low SA, Dickinson JR, Sotoudeh C, Clark JD, Barres A, Bohlen CJ, et al. (2017) Loss of $\mu$ opioid receptor signaling in nociceptors, but not microglia, abrogates morphine tolerance without disrupting analgesia. Nat Med 23:164-173.

Deng L, Cornett BL, Mackie K, and Hohmann AG (2015a) CB1 knockout mice unveil sustained CB2-mediated antiallodynic effects of the mixed CB1/CB2 agonist CP55,940 in a mouse model of paclitaxel-induced neuropathic pain. Mol Pharmacol 88:64-74.

Deng L, Guindon J, Cornett BL, Makriyannis A, Mackie K, and Hohmann AG (2015b) Chronic cannabinoid receptor 2 activation reverses paclitaxel neuropathy without tolerance or cannabinoid receptor 1-dependent withdrawal. Biol Psychiatry 77: 475-487.

Deng L, Guindon J, Vemuri VK, Thakur GA, White FA, Makriyannis A, and Hohmann AG (2012) The maintenance of cisplatin- and paclitaxel-induced mechanical and cold allodynia is suppressed by cannabinoid $\mathrm{CB}_{2}$ receptor activation and independent of CXCR4 signaling in models of chemotherapy-induced peripheral neuropathy. Mol Pain 8:71.

Dhopeshwarkar A and Mackie K (2016) Functional selectivity of CB2 cannabinoid receptor ligands at a canonical and noncanonical pathway. J Pharmacol Exp Ther 358:342-351.

Dhopeshwarkar A, Murataeva N, Makriyannis A, Straiker A, and Mackie K (2017) Two Janus cannabinoids that are both CB2 agonists and CB1 antagonists. $J$ Pharmacol Exp Ther 360:300-311.

Felder CC, Joyce KE, Briley EM, Mansouri J, Mackie K, Blond O, Lai Y, Ma AL, and Mitchell RL (1995) Comparison of the pharmacology and signal transduction of the human cannabinoid CB1 and CB2 receptors. Mol Pharmacol 48:443-450. 
Galiègue S, Mary S, Marchand J, Dussossoy D, Carrière D, Carayon P, Bouaboula M, Shire D, Le Fur G, and Casellas P (1995) Expression of central and peripheral cannabinoid receptors in human immune tissues and leukocyte subpopulations. Eur J Biochem 232:54-61

Gao F, Zhang L-H, Su T-F, Li L, Zhou R, Peng M, Wu C-H, Yuan X-C, Sun N, Meng XF, et al. (2016) Signaling mechanism of cannabinoid receptor-2 activation-induced $\beta$-Endorphin release. Mol Neurobiol 53:3616-3625.

Giblin GMP, O’Shaughnessy CT, Naylor A, Mitchell WL, Eatherton AJ, Slingsby BP, Rawlings DA, Goldsmith P, Brown AJ, Haslam CP, et al. (2007) Discovery of 2-[(2,4 Dichlorophenyl)amino]-N-[(tetrahydro- 2H-pyran-4-yl)methyl]-4-(trifluoromethyl)5-pyrimidinecarboxamide, a selective CB2 receptor agonist for the treatment of inflammatory pain. $J$ Med Chem 50:2597-2600.

Grace PM, Maier SF, and Watkins LR (2015) Opioid-induced central immune signaling: implications for opioid analgesia. Headache 55:475-489.

Griffin G, Tao Q, and Abood ME (2000) Cloning and pharmacological characterization of the rat $\mathrm{CB}(2)$ cannabinoid receptor. $J$ Pharmacol Exp Ther 292:886-894.

Guindon J and Hohmann AG (2008) Cannabinoid CB2 receptors: a therapeutic target for the treatment of inflammatory and neuropathic pain. $\mathrm{Br} J$ Pharmacol 153 319-334.

Herkenham M, Lynn AB, Johnson MR, Melvin LS, de Costa BR, and Rice KC (1991) Characterization and localization of cannabinoid receptors in rat brain: a quantitative in vitro autoradiographic study. J Neurosci 11:563-583.

Hsieh GC, Pai M, Chandran P, Hooker BA, Zhu CZ, Salyers AK, Wensink EJ, Zhan C, Carroll WA, Dart MJ, et al. (2011) Central and peripheral sites of action for $\mathrm{CB}_{2}$ receptor mediated analgesic activity in chronic inflammatory and neuropathic pain models in rats. Br J Pharmacol 162:428-440.

Khanolkar AD, Lu D, Ibrahim M, Duclos RI Jr, Thakur GA, Malan TP Jr, Porreca F, Veerappan V, Tian X, George C, et al. (2007) Cannabilactones: a novel class of CB2 selective agonists with peripheral analgesic activity. J Med Chem 50: 6493-6500.

Li A-L, Carey LM, Mackie K, and Hohmann AG (2017) Cannabinoid CB2 agonist GW405833 suppresses inflammatory and neuropathic pain through a CB1 mechanism that is independent of CB2 receptors in mice. J Pharmacol Exp Ther $\mathbf{3 6 2}$ $296-305$.

Lin X, Dhopeshwarkar AS, Huibregtse M, Mackie K, and Hohmann AG (2017) Slowly signaling $\mathrm{G}$ protein-biased $\mathrm{CB}_{2}$ cannabinoid receptor agonist LY2828360 suppresses neuropathic pain with sustained efficacy and attenuates morphine tolerance and dependence. Mol Pharmacol 93:49-62.

Malan TP Jr, Ibrahim MM, Lai J, Vanderah TW, Makriyannis A, and Porreca F (2003) CB2 cannabinoid receptor agonists: pain relief without psychoactive effects? Curr Opin Pharmacol 3:62-67.

Matsuda LA, Bonner TI, and Lolait SJ (1993) Localization of cannabinoid receptor mRNA in rat brain. $J$ Comp Neurol 327:535-550.

Merighi S, Gessi S, Varani K, Fazzi D, Mirandola P, and Borea PA (2012) Cannabinoid $\mathrm{CB}(2)$ receptor attenuates morphine-induced inflammatory responses in activated microglial cells. Br J Pharmacol 166:2371-2385.

Mukherjee S, Adams M, Whiteaker K, Daza A, Kage K, Cassar S, Meyer M, and Yao BB (2004) Species comparison and pharmacological characterization of rat and human CB2 cannabinoid receptors. Eur J Pharmacol 505:1-9.

Patel S, Naeem S, Kesingland A, Froestl W, Capogna M, Urban L, and Fox A (2001) The effects of GABA(B) agonists and gabapentin on mechanical hyperalgesia in models of neuropathic and inflammatory pain in the rat. Pain 90:217-226.

Pertwee RG (2001) Cannabinoid receptors and pain. Prog Neurobiol 63:569-611.

Rahn EJ, Deng L, Thakur GA, Vemuri K, Zvonok AM, Lai YY, Makriyannis A, and Hohmann AG (2014) Prophylactic cannabinoid administration blocks the development of paclitaxel-induced neuropathic nociception during analgesic treatment and following cessation of drug delivery. Mol Pain 10:27.

Rahn EJ, Thakur GA, Wood JAT, Zvonok AM, Makriyannis A, and Hohmann AG (2011) Pharmacological characterization of AM1710, a putative cannabinoid CB2 agonist from the cannabilactone class: antinociception without central nervous system side-effects. Pharmacol Biochem Behav 98:493-502.

Rahn EJ, Zvonok AM, Thakur GA, Khanolkar AD, Makriyannis A, and Hohmann AG (2008) Selective activation of cannabinoid CB2 receptors suppresses neuropathic nociception induced by treatment with the chemotherapeutic agent paclitaxel in rats. J Pharmacol Exp Ther 327:584-591.

Volkow N, Benveniste H, and McLellan AT (2018) Use and misuse of opioids in chronic pain. Annu Rev Med 69:451-465.

Wang T, Wang H, Ichijo H, Giannakakou P, Foster JS, Fojo T, and Wimalasena J (1998) Microtubule-interfering agents activate c-Jun N-terminal kinase/stressactivated protein kinase through both Ras and apoptosis signal-regulating kinase pathways. J Biol Chem 273:4928-4936.

Watkins LR, Hutchinson MR, Johnston IN, and Maier SF (2005) Glia: novel counterregulators of opioid analgesia. Trends Neurosci 28:661-669.

Watkins LR, Hutchinson MR, Rice KC, and Maier SF (2009) The "toll" of opioidinduced glial activation: improving the clinical efficacy of opioids by targeting glia. Trends Pharmacol Sci 30:581-591.

Wilkerson JL, Gentry KR, Dengler EC, Wallace JA, Kerwin AA, Armijo LM, Kuhn MN, Thakur GA, Makriyannis A, and Milligan ED (2012) Intrathecal cannabilactone $\mathrm{CB}(2) \mathrm{R}$ agonist, $\mathrm{AM} 1710$, controls pathological pain and restores basal cytokine levels. Pain 153:1091-1106.

Yamamoto W, Mikami T, and Iwamura H (2008) Involvement of central cannabinoid CB2 receptor in reducing mechanical allodynia in a mouse model of neuropathic pain. Eur J Pharmacol 583:56-61.

Yao BB, Hsieh G, Daza AV, Fan Y, Grayson GK, Garrison TR, El Kouhen O, Hooker BA, Pai M, Wensink EJ, et al. (2009) Characterization of a cannabinoid CB2 receptor-selective agonist, A-836339 [2,2,3,3-tetramethyl-cyclopropanecarboxylic acid [3-(2-methoxy-ethyl)-4,5-dimethyl-3H-thiazol-(2Z)-ylidene]-amide], using in vitro pharmacological assays, in vivo pain models, and pharmacological magnetic resonance imaging. $J$ Pharmacol Exp Ther 328:141-151.

Yao BB, Hsieh GC, Frost JM, Fan Y, Garrison TR, Daza AV, Grayson GK, Zhu CZ, Pai M, Chandran P, et al. (2008) In vitro and in vivo characterization of A-796260 a selective cannabinoid CB2 receptor agonist exhibiting analgesic activity in rodent pain models. Br J Pharmacol 153:390-401.

Yekkirala AS, Roberson DP, Bean BP, and Woolf CJ (2017) Breaking barriers to novel analgesic drug development. Nat Rev Drug Discov 16:545-564.

Zhang J, Hoffert C, Vu HK, Groblewski T, Ahmad S, and O'Donnell D (2003) Induction of CB2 receptor expression in the rat spinal cord of neuropathic but not inflammatory chronic pain models. Eur $J$ Neurosci 17:2750-2754.

Zhang M, Wang K, Ma M, Tian S, Wei N, and Wang G (2016) Low-dose cannabinoid type 2 receptor agonist attenuates tolerance to repeated morphine administration via regulating $\mu$-opioid receptor expression in walker 256 tumor-bearing rats. Anesth Analg 122:1031-1037.

Zimmermann M (1983) Ethical guidelines for investigations of experimental pain in conscious animals. Pain 16:109-110.

Address correspondence to: Andrea G. Hohmann, Psychological and Brain Sciences, Gill Center for Biomolecular Sciences, Indiana University, Bloomington, IN 47405. E-mail: hohmanna@indiana.edu 